1 A regulatory protein that represses sporulation in

\title{
Clostridioides difficile
}

3

4

5

DIOGO MARTINS, ARISTIDES L. MENDES, JESSICA ANTUNES, ADRIANO O. HENRIQUES AND MÓNICA SERRANO*

8

9 República, 2780-157 Oeiras, Portugal

14 *Corresponding author: Telf. +351-21-4469524; Fax. +351-21-4411277; e-mail

15 address: serrano@itqb.unl.pt

17 Running title: Inhibition of sporulation initiation in C. difficile

18 Key words: Sporulation; Clostridioides difficile; Anaerobe; Spo0A 


\section{Abstract}

20 Bacteria that reside in the gastrointestinal tract of healthy humans are essential for

21 our health, sustenance and well-being. About 50 to $60 \%$ of those bacteria have the ability to produce resilient spores, important for the life cycle in the gut and for hostto-host transmission. A genomic signature for sporulation in the human intestine was recently described, which spans both commensals and pathogens such as Clostridioides difficile, and contains several genes of unknown function. We report on the characterization of a signature gene, $\operatorname{csi} A$, which, as we show, is involved in the control of sporulation initiation in $C$. difficile. Spo0A is the main regulatory protein controlling entry into sporulation and we show that an in-frame deletion of csiA results in increased sporulation, and increased expression of spo0A per cell. Spo0A also drives transcription of the spollA and spollG operons, coding for the first forespore- $\left(\sigma^{F}\right)$ and mother cell-specific $\left(\sigma^{\mathrm{E}}\right)$ RNA polymerase sigma factors.

Strikingly, deletion of $c s i A$ increases expression of the spol/G operon, but not that of the spollA operon. Increased expression of spollG results in increased production and proteolytic activation of pro- $\sigma^{\mathrm{E}}$, suggesting that normally, the levels of active $\sigma^{\mathrm{E}}$ are limiting for sporulation. While other regulatory proteins affect both sporulation and several processes during the transition phase of growth, including toxin production or motility, deletion of the csiA gene does not alter the expression of the genes coding for the TcdA and TcdB cytotoxins or the genes involved in motility. Thus, our results establish that CsiA acts to modulate sporulation by reducing expression of the spo0A gene. 


\section{Introduction}

Many members of the Firmicutes phylum produce endospores (hereafter spores for simplicity), resilient and metabolically dormant structures that can remain viable for long periods of time. A large proportion of recently identified members of the human gut microbiota are spore formers and many of which are anaerobic organisms (Almeida et al., 2019, Browne et al., 2016). For anaerobic bacteria, pathogens or commensals, the production of oxygen-resistant spores is an important mechanism for transmission between hosts and persistence inside and outside the host (Browne et al., 2016). Gut spore forming bacteria are important members of the human commensal microbiota that only in rare cases cause opportunistic infections (Atarashi et al., 2011, Browne et al., 2016). Other spore formers, however, have evolved to become dedicated pathogens that can cause a striking variety of diseases. Despite variations in disease presentation, the infectious agent is often the spore, with toxins produced by the actively growing cells that result from spore germination playing a central role in the pathophysiology of infection (Zhu et al., 2018). One example is Clostridioides difficile, a spore-former obligate anaerobe. $C$. difficile is a major nosocomial pathogen and the main causative agent of a range of intestinal diseases associated with antibiotic therapy in adults (Carroll \& Bartlett, 2011). asymmetric division originating two compartments of unequal sizes, the large mother cell and the small forespore (Errington, 2003, Higgins \& Dworkin, 2012,

64 Piggot \& Hilbert, 2004)(Fig. 1A). The forespore and the mother cell will follow different lines of gene expression (Fimlaid et al., 2013, Pereira et al., 2013, Saujet 
response regulator, a transcription factor conserved among spore formers and essential for sporulation initiation in all organisms in which its function was experimentally assessed (Abecasis et al., 2013, Galperin et al., 2012, Traag et al., 2013). The role of Spo0A in sporulation has been studied in detail in Bacillus subtilis (reviewed in (Deakin et al., 2012, Fujita \& Losick, 2005, Molle et al., 2003, Pettit et al., 2014, Sonenshein, 2000)). In pre-divisional cells, the Spo0A-encoding gene, spo0A, is transcribed under the control of $\sigma^{\mathrm{A}}$ and $\sigma^{\mathrm{H}}$ (Pettit et al., 2014). Spo0A is post-translationally activated via phosphorylation by a phosphorelay consisting of several sensor kinases and phosphortransfer proteins, with multiple points of control of the flow of phosphate to Spo0A. The kinases respond to external signals by auto-phosphorylating and subsequently transferring a phosphate residue via the intermediary proteins SpoOF and Spo0B to Spo0A (Jiang et al., 2000). In contrast, no Spo0F or Spo0B homologs are found in $C$. difficile, and therefore presumably no phosphorelay is present; rather, Spo0A is believed to be phosphorylated directly by orphan histidine kinases that respond to as yet unknown signals (Steiner et al., 2011, Underwood et al., 2009, Worner et al., 2006). The $C$. difficile genome codes for five orphan kinases, three of which, CD1492, CD1579 and CD2492, share a high degree of sequence similarity with the sensor histidine kinases involved in the B. subtilis phosphorelay (Underwood et al., 2009). These three kinases were initially proposed to be responsible for Spo0A

87 phosphorylation. CD1579, however, was the only kinase shown to directly

88 phosphorylate Spo0A. CD2492 was proposed to positively regulate sporulation

89 (Underwood et al., 2009), however no complementation was shown for the mutant.

90 In contrast, CD1492 is now known to inhibit sporulation initiation and to affect toxin 91 and motility through the regulatory proteins RstA and SigD (Childress et al., 2016). 
In C. difficile, Spo0A controls approximately 300 genes (Fimlaid et al., 2013,

93 Pettit et al., 2014), which have been linked to biofilm formation, swimming motility,

94 toxin production and sporulation (Dawson et al., 2012, Fujita \& Losick, 2005, Pettit

et al., 2014, Underwood et al., 2009). Among the latter, are the genes coding for

96 the first cell type-specific regulators of sporulation, $\left(\sigma^{F}\right.$ and $\left.\sigma^{E}\right)$, as well as genes

97 required for the asymmetric division of the cell at the onset of sporulation

98 (Errington, 2003, Higgins \& Dworkin, 2012, Pettit et al., 2014, Piggot \& Hilbert,

99 2004, Rosenbusch et al., 2012).

100 Following asymmetric division, the mother cell initiates engulfment of the

101 forespore, a process with similarities to phagocytosis (Fig. 1A). At this stage, the

102 forespore is surrounded by an inner and outer membranes, that derive from the

103 polar division septum. Following engulfment completion, two types of

104 peptidoglycan are layered between the inner and outer membranes surrounding

105 the forespore. The surface of the inner spore membrane is the site of assembly of

106 a thin layer of peptidoglycan called primordial cell wall, similar in composition to the

107 vegetative cell wall. A second, thicker layer of chemically distinct peptidoglycan,

108 called the spore cortex, is assembled across the forespore outer membrane, which

109 faces the mother cell cytoplasm. The spore cortex is essential for the attainment

110 and maintenance of the dehydrated state of the spore core, and hence for heat

111 resistance and dormancy (Henriques \& Moran, 2007). Finally, in C. difficile, the

112 ordered assembly of proteins produced in the mother cell, form the coat and the

113 exosporium (Henriques \& Moran, 2007, Paredes-Sabja et al., 2014, Stewart,

114 2015). These proteinaceous layers protect the cortex against the action of

115 peptidoglycan-breaking enzymes, confer protection against small noxious

116 molecules and UV light, and influence the interaction of spores with molecules able 
117 to trigger germination (Driks \& Eichenberger, 2016, Henriques \& Moran, 2007,

118 McKenney et al., 2013). In addition, the exosporium plays an important role not

119 only in the adhesion of spores to abiotic surfaces but also to host cells (Stewart,

120 2015). At the end of the sporulation process the mother-cell lyses, releasing the

121 spore into the environment.

We previously established a genomic signature for sporulation, defined as

the genes found in $90 \%$ of the endospore forming bacteria, and present in no more

124 than 10\% of the non-spore-formers ((Abecasis et al., 2013); Fig. 1B). This

125 signature not only allows prediction of spore formation by organisms for which

126 sporulation has not been shown in the laboratory, but it also identified new genes

127 involved in sporulation (Abecasis et al., 2013). More recently, a genomic signature

128 for endosporulation in the human gastro-intestinal tract was established ((Browne

129 et al., 2016); Fig. 1B). This signature includes 65 genes and is dominated by

130 genes with a known function in sporulation. Approximately $30 \%$ of the signature

131 genes, however, have no known function in sporulation and/or code for products

132 with no similarity to known proteins; nevertheless, their presence in a genomic

133 signature for sporulation suggests a role in spore development, at least in the gut.

134 One of these genes is $C D 25890$ (Fig. 1B) and here we show that deletion of

135 CD25890 increases the expression of $s p o 0 A$, and also the expression of the

136 Spo0A- and $\sigma^{A}$-dependent spollG operon, coding for the first mother cell specific

137 RNA polymerase sigma factor, $\sigma^{\mathrm{E}}$. In contrast, deletion of $C D 25890$ does not

138 increases the expression of the SpoOA- and $\sigma^{H}$-dependent spollA operon, coding

139 for the first forespore-specific sigma factor, $\sigma^{F}$. Expression of the spol/G operon

140 results in the production of an inactive form of $\sigma^{\mathrm{E}}$, pro- $\sigma^{\mathrm{E}}$. Cleavage of pro- $\sigma^{\mathrm{E}}$

141 requires a forespore signalling protein, which in $C$. difficile is mostly but not 
Martins et al.

142 completely dependent on $\sigma^{F}$ (Fimlaid et al., 2013, Pereira et al., 2013, Saujet et

143 al., 2013). Strikingly, increased expression of spollG in the CD25890 mutant

144 results in increased production and proteolytic activation of pro- $\sigma^{\mathrm{E}}$, suggesting that

145 the levels of active $\sigma^{\mathrm{E}}$, and not forespore signalling, are a limiting factor for

146 sporulation. Deletion of the CD25890 gene does not alter the expression of the

147 gene coding for the TcdA cytotoxin, or the genes involved in motility, or biofilm

148 formation. Based on these phenotypes we renamed the CD25890 locus CsiA, to

149 reflect its role in the control of sporulation initiation. 


\section{Results}

\section{Functional analysis of a csiA mutant}

152 Phylogenetically, the csiA gene and its genomic context are highly

153 conserved within the Firmicutes (Fig. S1). In each genome we examined, CsiA is

154 encoded immediately upstream of the gmk gene encoding a guanylate kinase or of

155 the remA gene encoding a biofilm regulatory protein (Winkelman et al., 2009,

156 Winkelman et al., 2013). These genes are always upstream of the rpoZ gene,

157 encoding for the RNA polymerase omega subunit. Although its genomic context is

158 conserved, there is no evidence for the possible function of $c$ siA. Neverthelss, its

159 inclusion in a genomic signature for sporulation suggested an important role in this

160 developmental process. We started by the phenotypic characterization of a mutant

161 in the $\operatorname{csi} A$ gene. An in-frame deletion mutant of $c s i A$, lacking codons $5-291$ of the

162 294-codons-long open reading frame was generated by allelic-coupled exchange

163 (ACE) in the background of the widely used 630 4 erm strain (Fig. 1C; Fig. S2;

164 Table S1; (Ng et al., 2013)). The mutant was then complemented in single copy

165 upon restoration of the pyrE gene (Fig. S2).

166 We then examined cultures of the csiA mutant after $14 \mathrm{~h}$ of incubation on

167 sporulation liquid medium (SM). SM has been shown to efficiently induce

168 sporulation in strain $630 \Delta$ erm and is well suited for kinetics analyses and

169 fluorescence microscopy (Pereira et al., 2013, Wilson et al., 1982). The cells were

170 stained with the lipophilic membrane dye FM4-64, which allows identification of the

171 stages of sporulation up to engulfment completion, prior to imaging by phase

172 contrast and fluorescence microscopy (Pereira et al., 2013). As shown in Fig. S3A,

173 the csiA mutant presents more cells with signs of sporulation than the wild-type 
174 strain as determined by fluorescence and phase-contrast microscopy $(630 \Delta e r m$,

$17529 \% ; \Delta c s i A, 69 \%)$.

176 To rule out that the increased sporulation phenotype came from differences

177 in vegetative growth, the wild-type and the csiA mutant strains were grown in SM

178 and the optical density of the cultures was measured at $600 \mathrm{~nm}\left(\mathrm{OD}_{600}\right)$ at two-

179 hour intervals for 20 hours after inoculation. Both strains showed similar growth

180 patterns and, after about 10 hours, both entered in stationary phase (Fig. S3B).

181 Therefore, the csiA mutation does not affect growth of $C$. difficile under the

182 conditions tested.

183 To determine whether the kinetics of sporulation was altered in the csiA

184 mutant, we analysed the formation of heat resistant spores along time. Strains

185 were grown in SM broth, and at 12, 24, 48 and 72 hours the titer of heat resistant

$186 \mathrm{spores} / \mathrm{ml}$ of culture was determined as described in the materials and methods

187 section (Fig. 2A and Table 1). In line with earlier results (Pereira et al., 2013), the

188 titer of spores for the wild-type strain increased from $7.5 \times 10^{3}$ spores $/ \mathrm{ml}$ at hour 12 ,

189 to $1.0 \times 10^{4}$ spores $/ \mathrm{ml}$ at hour $24,1.3 \times 10^{5}$ spores $/ \mathrm{ml}$ at hour 48 and $1.7 \times 10^{5}$

190 spores/ml at hour 72 (Fig. 2A and Table 1). As expected from the previous results,

191 the csiA mutation did not affect cell viability (Table 1). In contrast, the titer of heat

192 resistant spores in the mutant strain was higher than the wild-type for all time

193 points: $3.1 \times 10^{4}, 8.5 \times 10^{4}$ spores $/ \mathrm{mL}, 1.5 \times 10^{6}$ and $2.2 \times 10^{6}$ spores $/ \mathrm{mL}$ at hour 12,24 ,

19448 and 72, respectively (Fig. 2A and Table 1). To determine whether the csiA

195 deletion was responsible for the mutant phenotype, sporulation was assessed in

196 the complemented strain (Table 1). As shown in Fig. 2A and Table 1,

197 complementation restored the wild-type kinetics of spore formation $\left(1.8 \times 10^{4}\right.$,

$1981.5 \times 10^{4}, 7.8 \times 10^{4}$ and $6.0 \times 10^{4}$ spores $/ \mathrm{ml}$ at hour $12,24,48$ and 72 , respectively). 
199 Thus, the deletion of $c$ siA is responsible for the increased sporulation frequency of 200 the mutant.

201 A second frequently used method to induce sporulation is growth on $70: 30$ 202 agar plates, in which the rate of sporulation is higher (Putnam et al., 2013). We 203 also tested the sporulation efficiency of the csiA mutant in this medium. When 204 sporulation was induced by this method, the csiA mutant shows a percentage of 205 sporulation similar to the wild-type strain (Fig. S4A). Thus, the culture medium 206 influences the csiA mutant phenotype (see also below).

\section{csiA negatively impacts sporulation}

We next followed progress through the morphological stages of sporulation 210 in SM, by phase contrast and fluorescence microscopy (Pereira et al., 2013). The 211 wild-type and the mutant strain were grown in SM and samples were collected 8, $21210,12,14,16,18$ and 20 hours after inoculation. The cells were stained with the 213 lipophilic membrane dye FM4-64 prior to microscopic examination. Cells

214 representative of several distinctive morphological classes are shown on Fig. 2B.

215 The results shown in Fig. 2C demonstrate that 8 hours after inoculation a 216 significant fraction of the csiA cells had undergone polar division (class a). In 217 contrast, class a cells were detected for the wild-type strain 2 hours later than in 218 the mutant. Moreover, phase bright spores (class e) were observed at 14 hours for 219 the mutant and at 18 hours for the wild-type strain.

220 To test whether spore morphogenesis proceeded faster in the csiA mutant, 221 we determined the time at which at least $10 \%$ of the cell population had undergone 222 polar division (class a), initiated engulfment (class $b$ ), showed complete engulfment 223 of the forespore by the mother cell (class $c$ ), or presented phase-gray or phase- 
224 bright spores (classes $d$ and $f$ ). The results in Fig. 2D show that progress through

225 these stages of sporulation occurred at the same pace for the two strains. We

226 conclude that the csiA mutant initiated sporulation earlier than the parental wild-

227 type or that the fraction of cells entering sporulation at the end of growth is larger

228 for the mutant. In any event, CsiA negatively affects the entry into sporulation.

\section{CsiA accumulates during growth independently of Spo0A}

We further investigated accumulation of CsiA during growth and sporulation in SM by immunoblot analysis using an anti-CsiA antibody (Fig. 3A). CsiA starts to accumulate early during growth and is present also during entry into stationary

234 phase when the cells start to sporulate. No signal is detected in the csiA mutant, 235 while its accumulation is restored in the complementation strain, confirming the 236 specificity of the antibody. CsiA accumulation is independent of SpoOA, the master 237 regulator of sporulation (Fig. 3B). These results show that CsiA starts to 238 accumulate during vegetative growth, independently of the main sporulation 239 transcription regulators.

\section{Deletion of $c s i A$ increases transcription of $s p o 0 A$}

244 we wanted to test whether deletion of $c \operatorname{si}$ increased the expression of the $s p 00 \mathrm{~A}$

245 gene in individual cells. We constructed a fusion of the spoOA promotor region to 246 the SNAP reporter and we introduced the $\mathrm{P}_{\text {spooA }}-S N A P$ fusion in the csiA mutant 247 and in the parental wild-type strain (Table S1). To monitor production of SNAP, 
248 samples of cultures expressing the transcriptional fusion were collected 10 hours

249 after inoculation in SM and the cells were labelled with the TMR-Star SNAP

250 substrate (Fig. 4A). Expression of $\mathrm{P}_{\text {spooA }}$-SNAP was detected in $100 \%$ of the cells

251 for both the wild-type and the csiA mutant (Fig. 4A). Quantification of the

252 fluorescence signal per cell (in arbitrary units, or AU; Fig. 4B), however, shows that

253 transcription from the spo0A promoter occurred at a lower intensity in the wild-type

254 (average signal, 137.6 AU) as compared to the csiA mutant (average signal, 277.3

255 AU) (Fig. 4B).

256 To investigate whether the increased transcription from the spo0A promoter

257 could also lead to increased accumulation of Spo0A, we compared the levels of

258 Spo0A throughout sporulation by immunoblot analysis using a previously described

259 anti-Spo0A antibody ((Serra et al., 2014); Fig. 4C). We found that Spo0A is

260 detected as early as 6 hours following inoculation in SM for all strains, but that in

261 the csiA mutant Spo0A accumulates at greater levels than in the wild-type or the

262 complementation strain (Fig. 4C). Together, these results suggest that more cells

263 of the mutant reach a threshold level of Spo0A that triggers sporulation, and that

264 CsiA antagonizes expression of spoOA and/or the activity of Spo0A, since spoOA is 265 subject to positive auto-regulation (Rosenbusch et al., 2012).

266 Since we did not observe a phenotype for the csiA mutant when sporulation

267 was induced on 70:30 medium (see above), we compared the expression of spo0A

268 in SM with that in 70:30 medium using fluorescence microscopy and single cell

269 analysis (Fig. S3B). Quantification of the fluorescence signal per cell (Fig. S4B)

270 shows that transcription from the spo0A promoter is higher in 70:30 medium in

271 both the wild-type (average signal, 267.1 AU) and csiA mutant (average signal,

$272332.8 \mathrm{AU})$, reaching levels similar to those observed in the mutant when 
273 sporulation is induced in SM (average signal,372 AU) (Fig. S4B). This result

274 suggests that in 70:30 medium, the wild-type strain reaches the threshold levels of

275 spoOA required for sporulation in a higher number of cells than in SM, similar to

276 what was observed for the csiA mutant in both media. Hence, CsiA acts as a

277 repressor only under certain culturing conditions that induce sporulation, with the

278 effect of the csiA mutation being masked in 70:30. medium

\section{Phosphorylated Spo0A accumulates at higher levels in the csiA mutant}

Spo0A is activated by phosphorylation (Fujita \& Sadaie, 1998, Lewis et al., 1999). The activated Spo0A protein, Spo0A P, binds to DNA promoter regions containing a Spo0A-binding motif and then regulates the expression of Spo0Adependent genes. Since spo0A is auto-regulatory, and higher expression per cell is seen in the csiA mutant in SM, we asked whether Spo0A P would accumulate at higher levels in the mutant. For this, we used Phos-tag SDS-PAGE, where migration of Spo0A P is delayed, and the two forms (phosphorylated and unphosphorylated) are then detected by western blot using anti-Spo0A antibodies.

The wild-type and the mutant strain were grown in SM and samples were collected

$2906,8,10$ and 12 hours after inoculation. Whole cell extracts were prepared and the 291 proteins resolved by Phos-tag SDS-PAGE (Fig. 5A). Two bands were detected in 292 this manner. The upper band disappeared when the samples were boiled prior to 293 electrophoretic resolution, which indicates that the upper band corresponds to 294 Spo0A P and the lower band to the unphosphorylated form (Yasugi et al., 2016). 295 We found that in the csiA mutant, both forms of SpoOA accumulate earlier and at 296 higher levels than in the wild-type. We then quantified band intensities in order to 
298 (Spo0A P/Spo0A) using Image-J software. The Spo0A P/Spo0A ratio was higher

299 at hour 8 and 10 in the mutant as compared to the wild-type strain (Fig. 5B).

300 However, at hour 12 the ratio between the two forms was similar between the two 301 strains.

This result suggests that the level of Spo0A phosphorylation is directly proportional to the level of the protein. Together with the observation that $s p o 0 A$ is expressed in most if not all of the pre-divisional cells (Fig. 4A), our findings suggest that phosphorylation of Spo0A is not a limiting factor for the initiation of sporulation. Possibly then, the level of $s p o 0 A$ per cell could limit entry into sporulation.

Since we found increased transcription of $\mathrm{P}_{\text {spooA }}-S N A P^{C d}$ in the $c s i A$ mutant, we reasoned that the increased sporulation in the mutant could be due to

311 increased transcription or to increased activity of Spo0A. To uncouple transcription

312 from activation of Spo0A by phosphorylation, we placed the spo0A gene under the 313 control of the anhydrotetracycline (ATc) responsive $\mathrm{P}_{\text {tet }}$ promoter (Dembek et al., 314 2017). In this way Spo0A could accumulate to similar levels in the wild-type and in 315 the csiA mutant strains, allowing us to test whether increased levels of Spo0A P 316 accumulated in the mutant. The strains were grown in SM supplemented with 50 $317 \mathrm{nM}$ of ATc, a concentration at which Spo0A accumulates to levels similar to the 318 wild-type strain (Dembek et al., 2017), and proteins in whole cells extracts were 319 resolved by Phos-tag SDS-PAGE (Fig. 5C). In both strains Spo0A accumulates at 320 similar levels and the Spo0A P/Spo0A ratio was similar (Fig. 5C and D). In 321 agreement with this observation, heat test revealed no difference in the number of 322 heat resistant spores produced by both strains (Table 2). 
Together these results suggest that CsiA acts mainly by decreasing the

324 levels of spo0A transcription per cell.

\section{The csiA mutant shows increased expression of Spo0A-dependent genes}

The increased expression of spoOA and the increased sporulation of the

331 transcription is under Spo0A control. To monitor transcription of sigE and sigF, we

332 used transcriptional fusions of the spollA (driving $\sigma^{F}$ production) and spollG (driving

$333 \sigma^{\mathrm{E}}$ production) promoters to the SNAP ${ }^{\mathrm{Cd}}$ reporter (Pereira et al., 2013). Samples of

334 cultures expressing each of the promoter- SNAP ${ }^{\mathrm{Cd}}$ fusions were collected 14 hours

335 after inoculation in SM and the cells labelled with TMR-Star and the membrane dye

336 MTG, to allow identification of the different stages of sporulation (Fig. 6A).

337 Expression of both sigF and sigE was first detected in pre-divisional cells and cells

338 that had undergone polar division, as reported previously (Pereira et al., 2013).

339 Quantification of the fluorescence signal shows that although for sigF the

340 percentage of cells with a fluorescence signal is higher in the csiA mutant (52\%)

341 than in the wild-type strain (35\%), the average intensity of the signal did not differ

342 much between the two strains (1187.05 AU for the wild type and 1110.50 AU for

343 the mutant) (Fig. 6B). Transcription of sigE, however, was lower in the wild-type,

344 with $76 \%$ of the cells showing a signal with an average intensity of $857.96 \mathrm{AU}$, as

345 compared to the mutant, in which $87 \%$ of cells showed a fluorescence signal with a

346 significantly higher average intensity of $1295.78 \mathrm{AU}$ (Fig. 6B). 
We next examined the effect of the csiA mutant on the activity of $\sigma^{\mathrm{F}}$ and $\sigma^{\mathrm{E}}$ by monitoring expression of transcriptional fusions of the gpr (controlled by $\sigma^{F}$ ) and spollIA (controlled by $\sigma^{\mathrm{E}}$ ) promoters to the SNAP ${ }^{\mathrm{Cd}}$ reporter (Pereira et al., 2013).

350 Expression of gpr was detected in $83 \%$ of the sporulating cells of the wild-type and 351 in $94 \%$ of the csiA sporangia (Fig. $6 \mathrm{~A}$ ), while expression of spolllA was detected in $35277 \%$ of the sporulating cells in the wild-type and in $91 \%$ of the csiA sporangia (Fig.

$3536 \mathrm{~A})$. A quantitative analysis revealed no effect of the csiA mutation on $\mathrm{gpr}$

354 expression (average intensity of 4412.30 AU for the wild type and 4551.54 AU for 355 the mutant; Fig. 6B). In contrast, the average intensity of the fluorescence signal 356 from $\mathrm{P}_{\text {spollIA- }}$ SNAP ${ }^{C d}$ was higher in cells of the mutant (1277.84 AU for the mutant) 357 as compared to the wid-type (827.90 AU) (Fig. 6B). This increase likely results from the augmented expression of sigE in the csiA mutant (see above).

Earlier accumulation and processing of pro- $\sigma^{\mathrm{E}}$ in the $\operatorname{csiA}$ mutant. accumulate to higher levels in cells of the csiA mutant as compared to the wild-type and that in contrast, the levels of $\sigma^{\mathrm{F}}$ would be similar in the mutant and the wild-

365 type. To test this prediction, we monitored the accumulation of $\sigma^{\mathrm{F}}$ and $\sigma^{\mathrm{E}}$ by 366 immunoblotting during entry into sporulation. The mature, active form of $\sigma^{\mathrm{E}}$ was 367 first detected 8 hours after inoculation in the mutant and only at 10 hours in the 368 wild-type (Fig. 6C). Importantly, we found that the accumulation of the mature form 369 of $\sigma^{\mathrm{E}}$ is also higher for the csiA mutant as compared to the wild-type, with the 370 protein accumulating at levels 8 times higher in the mutant 10 hours after 
371 inoculation (Fig. 6C). On the other hand, there was no significant difference on the

372 accumulation of $\sigma^{\mathrm{F}}$ between the wild-type and the mutant. Thus, the lack of CsiA

373 leads to premature accumulation and activation of pro- $\sigma^{\mathrm{E}}$, but does not affect the

374 accumulation of $\sigma^{\mathrm{F}}$.

376 Expression of sigE establishes a threshold for sporulation.

377 Higher levels of Spo0A P accumulate in the csiA mutant, leading to

378 increased expression of the Spo0A-dependent genes. Consequently, the higher

379 levels of Spo0A P increase the number of cells showing asymmetric division (Fig.

$3802 \mathrm{C})$, and on transcription from the spollG promoter, but not from the spollA

381 promoter (Fig. 6B). These results strongly suggest that asymmetric division and the

382 level of active $\sigma^{\mathrm{E}}$ are a limiting factor for sporulation. To test this idea we inserted

383 the $\mathrm{P}_{\text {sigF }}$ and $\mathrm{P}_{\text {sige- }}-S N A P^{C d}$ fusions in the strain in which $s p o 0 A$ is under the control

384 of $\mathrm{P}_{\text {tet }}$ promoter (Dembek et al., 2017). The strains were grown in SM to an $\mathrm{OD}_{600}$

385 of approximately 0.2 , supplemented with a range of ATc concentrations, from 0

$386250 \mathrm{ng} / \mathrm{ml}$, and 2 hours after addition the cells were labelled with TMR. In the

387 absence of the inducer, no fluorescence was detected in either strain. In contrast, a

388 clear dose-dependent response in the percentage of cells showing fluorescence

389 from the $\mathrm{P}_{\text {sige }}$-SNAP fusion was observed at concentrations of inducer from 0 to 50

$390 \mathrm{ng} / \mathrm{ml}$ (Fig. 6D), reaching a plateau at higher aTc concentrations (approximately

$39170 \%$ of the cells). Interestingly, this is also the concentration at which wild type

392 levels of heat resistance spores are reached in the strain carrying spo0A under $\mathrm{P}_{\text {tet }}$

393 control (Dembek et al., 2017). In contrast, low levels of spo0A (10 ng/ml) are

394 required to detect expression of sigF in nearly all of the cells in the population

395 (approximately 95\%; Fig. 6D). Since the formation the polar septum is also 
396 governed by Spo0A P (Ben-Yehuda \& Losick, 2002, Levin \& Losick, 1996), we

397 also measured the number of cells showing asymmetric septa in the $\mathrm{P}_{\text {tet }}$ spoOA

398 strain at the same range of ATc concentrations, following staining of the cells with

399 the membrane dye FM4-64 prior to microscopic examination (Fig. 6D). At $10 \mathrm{ng} / \mathrm{ml}$

400 of aTc only approximately $35 \%$ of the cells showed asymmetric septa or were at

401 intermediates stages during engulfment; this percentage increased to more than

$40290 \%$ at $25 \mathrm{ng} / \mathrm{ml}$ of aTc.

$403 \quad$ Thus, our results suggest that there are different Spo0A P thresholds for

404 the formation of the asymmetric septum, and for the activation of spollA and spol/G

405 transcription. At least under some conditions, a fraction of the cells that activate

406 spollA expression may not reach a point that allows spollG expression or

407 asymmetric division.

408

Deletion of csiA mainly affects sporulation

411 factors such as motility, biofilm formation and toxin production (Pettit et al., 2014,

412 Rosenbusch et al., 2012, Underwood et al., 2009). Therefore, we wanted to

413 determine whether the csiA mutation had a more global effect on gene expression,

414 for that we decided to compare the transcriptome of the mutant with the wild type

415 after 10 hours of growth in SM. We used two biological replicates and genes were

416 considered differentially expressed if the fold change was $>2$ and the adjusted $p$

417 value $<0.01$. We found that 165 genes were overexpressed in the mutant, while

418 only 21 genes were under-expressed (Table 3). From these genes, $69 \%$ are genes

419 regulated by Spo0A or by sporulation-specific cell type-specific sigma factors (Fig. 
$4207 \mathrm{~A}$ and Table 3). No toxin, biofilm or motility genes are among these genes (see 421 also Fig. S5).

422

\section{Discussion}

A genomic signature of sporulation in the human intestinal microbiome

425 (Browne et al., 2016) includes not only genes with an established function in

426 sporulation (Fig. 1) but also a group of 20 genes of unknown function. We

427 hypothesized that these uncharacterized genes are important for sporulation. To

428 test this hypothesis, we characterized a mutant in the csiA (CD25890) gene. We

429 show that the CsiA protein accumulates during growth in a medium in which

430 sporulation is induced, and also during sporulation (Fig. 3). Attempts to localise

431 csiA expression during sporulation using a SNAP transcriptional fusion to the 331

432 bp region upstream of $c$ siA failed, even if this same region is sufficient to allow the

433 expression of $c s i A$ at the pyrE locus at levels that permit complementation of the

434 csiA deletion mutation.

435 We found that under certain culturing conditions, csiA deletion has an

436 impact on sporulation. The csiA mutant reaches a higher titer of spores than the

437 wild type strain when grown in sporulation medium (SM). We show here that in the

438 csiA mutant spore differentiation is triggered in a larger fraction of the population

439 (Fig. 2). This mutant maintains high levels of spo0A expression and shows higher

440 expression of genes required for sporulation, such as spollG (Fig. 4 and 6). Since

441 Spo0A is auto-regulatory, the transcriptional fusion reports both transcription of

442 spoOA as well as the activity of Spo0A which requires phosphorylation of the

443 protein (Rosenbusch et al., 2012). We show that higher levels of Spo0A P 
444 accumulate in the csiA mutant earlier during growth, leading to increased

445 expression of Spo0A-dependent genes. Uncoupling of transcription from activation

446 by using an inducible promoter to control spo0A expression showed that CsiA does

447 not act on the phosphorylation of Spo0A but rather at the level of spoOA

448 transcription (Fig. 5). In cells growing in SM, Spo0A P is directly proportional to the 449 total level of protein, indicating that under these conditions phosphorylation is not a 450 limiting step for the initiation of sporulation.

Our finding that higher accumulation of Spo0A correlates with enhanced

452 sporulation contrasts with studies performed in B. subtilis, where accelerated

453 accumulation of Spo0A independent of the phosphorelay was detrimental to

454 sporulation (Fujita \& Losick, 2005, Vishnoi et al., 2013). Rather, Spo0A needs to

455 accumulate in a gradual manner to trigger sporulation and this requires its

456 phosphorylation through the phosphorelay (Vishnoi et al., 2013). This suggests that

457 a gradual build-up of Spo0A may not be important for the sporulation process in $C$.

458 difficile. Previous studies have already shown that spo0A expression can be

459 increased form an inducible promoter in a dose-dependent manner, and that the

460 level of expression correlates with sporulation efficiency, which reaches values

461 higher than those observed in a congenic wild-type strain (Dembek et al., 2017).

463 of the asymmetric septum, possibly through spolIE, which is also under the control

464 of Spo0A and is required for proper septum formation (Ben-Yehuda \& Losick,

465 2002, Levin \& Losick, 1996). The mutation also increased spollG transcription,

466 while not affecting spollA transcription (Fig. 2 and 6). These events are under the

467 control of Spo0A (Ben-Yehuda \& Losick, 2002, Levin \& Losick, 1996, Pettit et al.,

468 2014, Rosenbusch et al., 2012, Saujet et al., 2011). The spollA operon (spollAA- 
spollAB-sigf) is transcribed under the joint control of the $\sigma^{\mathrm{H}}$ sigma factor and

470 Spo0A, which binds to Spo0A boxes in the spollA promoter region (Pettit et al.,

4712014 , Rosenbusch et al., 2012, Saujet et al., 2011). Our results, however,

472 suggests that a factor or factors other than Spo0A contributes to expression of

473 sigF, as also shown in C. acetobutylicum (Alsaker et al., 2004). spollE is involved

474 in the Spo0A-dependent switch in the septum localization from mid-cell to the pole,

475 and its expression is also $\sigma^{\mathrm{H}}$ - and Spo0A-dependent (Ben-Yehuda \& Losick, 2002,

476 Khvorova et al., 1998, Levin \& Losick, 1996, Saujet et al., 2011). In contrast, the

477 spol/G operon (spol/GA-sigE) is under the control of $\sigma^{\mathrm{A}}$ and is also positively

478 regulated by Spo0A. Therefore, differences on the role of CsiA in the expression

479 from different promoters are unlikely to be related to the regulation of the $\sigma$ factor.

480 Rather, CsiA may affect the complexes made by $\sigma^{\mathrm{H}}$ and Spo0A and by $\sigma^{\mathrm{A}}$ and

481 Spo0A at different promoters.

482 In line with the $S N A P^{C d}$-based single cell transcriptional analysis, we also

483 found that accumulation of the active, processed form of $\sigma^{\mathrm{E}}$ is higher in the $\operatorname{csi} A$

484 mutant as compared to the wild-type. In contrast, there was no significant

485 differences on the accumulation of $\sigma^{\mathrm{F}}$. This is in agreement with previous results

486 showing that the expression of the $\sigma^{\mathrm{E}}$ regulon in the mother cell was not strictly

487 under the control of $\sigma^{F}$ (Saujet et al., 2013).

488 Previous studies have shown that the DNA-binding domain of Spo0A

489 (Spo0A-DBD) is able to bind to the promoter regions of sigF, spollE and sigE,

490 (Rosenbusch et al., 2012). Spo0A-DBD binds at low concentration to spollA and

491 spollE, and a higher concentration is needed to detect binding to the sigE

492 promoter. Here, we used a strain in which spo0A expression is under the control of

493 an inducible promoter (Dembek et al., 2017) to test for the requirement of different 
494 amounts of SpoOA to trigger sigF and sigE expression, as well as formation of

495 asymmetric septa (an event that is also under Spo0A control). Under the conditions

496 tested, phosphorylation was not a limiting step for sporulation (Fig. 5). Therefore,

497 we infer that the amount of spoOA expression is proportional to the level of

498 Spo0A P. We found that expression from the spollA promoter increases

499 dramatically at low levels of spo0A expression (10 $\mathrm{ng} / \mathrm{ml}$ of the inducer aTc), while

500 higher levels of $s p o 0 A$ expression ( $250 \mathrm{ng} / \mathrm{ml}$ of aTc) are required for $\operatorname{sig} E$ to be

501 expressed in the majority of the cells. Asymmetric division is achieved in almost

$502100 \%$ of the cells when spoOA was induced with $25 \mathrm{ng} / \mathrm{ml}$ of aTc (Fig. 6). We were

503 not able to detect spollE expression using a SNAP transcriptional fusion. These

504 results indicate that as in B. subtilis many of the spo0A-dependent genes respond

505 to the transcriptional factor in a dose-dependent manner (Fujita et al., 2005). In B.

506 subtilis the threshold of Spo0A activity required for $\sigma^{F}$ activation is below that for

507 the activation of $\sigma^{\mathrm{E}}$ (Narula et al., 2012). In B. subtilis, cells that form an

508 asymmetrical septum but do not activate $\sigma^{F}$ or $\sigma^{E}$ are able to resume vegetative

509 growth (Dworkin \& Losick, 2005); commitment to sporulation occurs only after the

510 activation of both of the first cell type-specific $\sigma$ factors, $\sigma^{F}$ and $\sigma^{\mathrm{E}}$. Since spore

511 formation is an energy consuming process and irreversible after specific points, in

512 C. difficile commitment to sporulation may be postponed until $\sigma^{\mathrm{E}}$ accumulates to

513 sufficient levels. This may be achieved by controlling spo0A expression, and csiA

514 may be involved in this process (Fig. 7D).

515 The impact of $c$ siA on sporulation and on expression of sporulation-specific

516 genes is significantly influenced by the culture medium. The two sporulation

517 conditions used here differ in medium composition, and this may indicate that the

518 signalling to enter sporulation may be different, dependent on the environment. 
519 The specific external signals that activate sporulation in C. difficile are not known,

520 but it is anticipated that, like in $B$. subtilis, the sporulation-initiating and -inhibiting

521 signals for C. difficile act on Spo0A (Childress et al., 2016, Underwood et al.,

522 2009).

Many factors that influence the sporulation pathway have been identified.

524 Two global regulators, CcpA and $\operatorname{CodY}$, affect the initiation of sporulation by

525 repressing the expression of sporulation-related genes in high-nutrient conditions

526 (Antunes et al., 2012, Dineen et al., 2007, Girinathan et al., 2018, Nawrocki et al.,

527 2016). Both of these transcription repressors also repress the expression of the

528 toxin encoding genes (Antunes et al., 2012). Another negative regulator of

529 sporulation initiation is the histidine kinase CD1492. The CD1492 mutant shows

530 increased expression of spo0A-dependent genes, but also exhibits decreased toxin

531 production and motility. RstA, acts as a positive regulator of sporulation, although

532 the exact nature of this effect remains unclear (Edwards et al., 2016). The DNA

533 binding domain of RstA was shown to directly bind to toxin and motility genes,

534 repressing their expression, but this domain is not required for the positive effect

535 exerted on sporulation (Edwards et al., 2019). The genome of $C$. difficile also

536 encodes for two oligopeptide permeases (Opp and App) that in B. subtilis are

537 involved in the control of sporulation initiation in a cell density-dependent manner

538 (Koide \& Hoch, 1994, Perego et al., 1991). Given the ecological niche of C. difficile,

539 cell density may not be a signal that triggers sporulation, and in contrast to $B$.

540 subtilis, the opp and app mutants show increased sporulation-specific gene

541 expression, and exhibit a hyper-sporulation phenotype with no impact on toxin

542 production or motility (Edwards et al., 2014). It was suggested that opp and app

543 may be involved in sporulation as a response to nutrient availability. Like csiA, 
544 these mutants also show an increase on the expression of the sinRR' operon

545 (Table 3), previously shown to be involved in sporulation, toxin production and

546 motility (Girinathan et al., 2018). It was shown that overexpression of $\sin R$

547 increased sporulation efficiency, while overexpression of sinR' reduced sporulation.

548 However, to our knowledge the overexpression of the entire operon, as occurs in

549 the csiA and opp, app mutants, was not tested. With the exception of the opp and

550 app peptide transporter mutants, all the mutants in genes involved in the control of

551 initiation of sporulation also have an impact on toxin production and/or motility.

552 Since deletion of $c$ siA has no impact on toxin production and motility, the csiA

553 function is most likely independent from SigD, RstA, CD1492, and CD2492. In

554 addition, csiA must not be impacting activity of CodY or CcpA, both of which also

555 affect toxin production.

556 B. subtilis csiA orthologue $(y / o C)$ is in an operon with the remA gene, which

557 was also previously identified as part of a sporulation genomic signature

558 ((Abecasis et al., 2013, Traag et al., 2013), Fig. S1, orange gene). RemA is

559 required for activating expression of the extracellular matrix biosynthetic operons

560 during biofilm development by undomesticated strains of $B$. subtilis (Winkelman et

561 al., 2009, Winkelman et al., 2013). While remA is not present in C. difficile and

562 neither YloC nor CsiA show sequence similarity to proteins of known function, the

563 genomic context suggested a role in the regulation of genes at the onset of the

564 stationary growth, which may have different outcomes in the two bacteria (biofilm

565 or sporulation) due to differences on the specific signals that lead to different

566 responses.

567 Our study has identified a new factor that affects sporulation initiation, CsiA, 568 which negative impacts sporulation by affecting the expression of spo0A. The 
569 medium dependence of CsiA function may reflect differences in nutrient-signalling

570 of spoOA expression and this observation may be explored to identify some of

571 those signals. In all, our analysis shows that the genomic signature of sporulation

572 within the human intestinal microbiome can be used to identify new genes

573 important during the sporulation process. Further studies are needed to

574 established the function of the other signature genes. This may lead to the

575 identification of new genetic determinants for spore formation whose products

576 could act as important targets for the design of drugs effective against all spore-

577 formers. 


\section{Materials and Methods}

581 Growth conditions and general methods. Bacterial strains and their relevant

582 properties are listed in Table S1. The Escherichia coli strain DH5a (Bethesda

583 Research laboratories) was used for molecular cloning, while the strain HB101

584 (RP4) was used as the donor in C. difficile conjugation experiments (Hussain et al.,

585 2005). Luria-Bertani medium was routinely used for growth and maintenance of $E$.

586 coli. When appropriate, ampicillin $(100 \mu \mathrm{g} / \mathrm{ml})$ or chloramphenicol $(15 \mu \mathrm{g} / \mathrm{ml})$ was

587 added to the culture medium. The $C$. difficile strains used in this study are isogenic

588 derivatives of the wild-type strain 630 $\Delta$ erm (Hussain et al., 2005) and were

589 routinely grown anaerobically $\left(5 \% \mathrm{H}_{2}, 15 \% \mathrm{CO}_{2}, 80 \% \mathrm{~N}_{2}\right)$ at $37^{\circ} \mathrm{C}$ in brain heart

590 infusion (BHI) medium (Difco) (Wilson et al., 1982). Assays for toxin production

591 were done in tryptone yeast extract (30g/L tryptone; $20 \mathrm{~g} / \mathrm{L}$ yeast extract) (TY).

592 When necessary, cefoxitin $(25 \mu \mathrm{g} / \mathrm{ml})$ and thiamphenicol $(15 \mu \mathrm{g} / \mathrm{ml})$ were added to

593 C. difficile cultures. A defined minimal media (CDMM) (Karasawa et al., 1995) with

$5941 \%$ agar was used as uracil-free medium when performing genetic selections.

595 Sporulation was tested on liquid Sporulation Medium (SM; for 1L: Bacto

596 tryptone $90 \mathrm{~g}$, Bacto peptone $5 \mathrm{~g},\left(\mathrm{NH}_{4}\right)_{2} \mathrm{SO}_{4} 1 \mathrm{~g}$, Tris base $1.5 \mathrm{~g}$, pH 7; (Pereira et

597 al., 2013)) and 70:30 agar medium (for 1L: Bacto peptone $63 \mathrm{~g}$, proteose peptone

$598 \quad 3.5 \mathrm{~g},\left(\mathrm{NH}_{4}\right)_{2} \mathrm{SO}_{4} 0.7 \mathrm{~g}$, Tris base $1.06 \mathrm{~g}$, brain heart infusion extract $11.1 \mathrm{~g}$, yeast

599 extract $1.5 \mathrm{~g}$, cysteine $0.3 \mathrm{~g}$ and agar $15 \mathrm{~g}$, (Putnam et al., 2013)). Sporulation was

600 regularly induced by inoculating in SM liquid. To determine the total number of

601 cells, the cells were serially diluted and plated on $\mathrm{BHI}$ with $0.1 \%$ taurocholate

602 (Sigma-Aldrich) to ensure efficient spore germination. To determine the number of 
603 spores, the cells were heat killed by incubation for $30 \mathrm{~min}$ at $70^{\circ} \mathrm{C}$ prior to plating

604 on $\mathrm{BHI}$ with $0.1 \%$ taurocholate.

605 Construction of the csiA mutant. A csiA in-frame deletion mutant was generated

606 using allele-couple exchange (ACE) in C. difficile 630 $\Delta$ erm $\Delta p y r E$ as described $(\mathrm{Ng}$

607 et al., 2013). The homology regions upstream and downstream of the desired

608 junction point within csiA were PCR-amplified and cloned into pMTL-YN3 as

609 follows ( $\mathrm{Ng}$ et al., 2013). The upstream fragment (742 bp) was amplified using the

610 primers csiA_Ascl_Fwd and csiA_LHA_Rev and the downstream fragment (735

611 bp) was amplified using the primers csiA_RHA_Fwd and csiA_Sbfl_Rev. The

612 fragments were then joined by overlapping PCR, the resulting fragment cleaved

613 with Ascl and Sbfl and cloned between the same sites of pMTL-YN3, yielding

614 pAM37. This plasmid was introduced into E. coli HB101 (RP4) and then transferred

615 to strain $630 \Delta$ erm $\Delta$ pyrE by conjugation (Heap et al., 2007). Following two

616 passages on $\mathrm{BHI}$ agar supplemented with $25 \mu \mathrm{g} / \mathrm{mL}$ cefoxitin and $15 \mu \mathrm{g} / \mathrm{mL}$

617 thiamphenicol, colonies that were noticeably larger (indicative of plasmid

618 integration) were screened by colony PCR to identify single-crossover mutants

619 using primers flanking the upstream and downstream homology regions in

620 conjunction with a plasmid-specific primer (P3 with P2 and P4 with P1) to amplify

621 across the integration junction (Fig. S2). Clones positives for single crossover

622 mutants were streaked onto $C$. difficile minimal medium (CDMM) supplemented

623 with $5 \mu \mathrm{g} / \mathrm{mL}$ uracil and $2 \mathrm{mg} / \mathrm{mL} 5$-fluoroorotic acid (FOA) to select for plasmid

624 excision. The isolated FOA-resistant colonies were screened by PCR using

625 primers P3 and P4. Double-crossover mutants, in which the mutant allele was

626 successfully integrated yielded products smaller than those seen in WT revertants

627 (1630 bp instead of $2472 \mathrm{bp}$ ). In order to restore the pyrE ${ }^{+}$phenotype, plasmid 
628 pMTL-YN1 carrying the WT pyrE allele was conjugated into the isolated double-

629 crossover mutants. The resulting colonies were restreaked onto non-supplemented

630 CDMM agar to select for uracil prototrophy indicating successful allele exchange.

631 Successful restoration of the WT pyrE allele was confirmed by colony PCR using

632 primers flanking the pyrE locus (P5 and P6, Fig. S2).

633 In trans complementation of the $\Delta$ csiA mutation. To complement the csiA

634 mutation the coding sequence and its expected promoter region were amplified by

635 PCR using primers csiA_Fwd_BamHI and csiA_Rev_Xhol yielding a $1515 \mathrm{bp}$

636 fragment. The fragment was then digested with BamHI and Xhol and inserted

637 between the same sites of pMTL-YN1 (Ng et al., 2013), yielding pAM38. This

638 plasmid was introduced into E. coli HB101 (RP4) and then transferred to strain

$639630 \Delta e r m \Delta p y r E \Delta c s i A$ by conjugation (Heap et al., 2007). Following two passages

640 on $\mathrm{BHI}$ agar supplemented with $25 \mu \mathrm{g} / \mathrm{mL}$ cefoxitin and $15 \mu \mathrm{g} / \mathrm{mL}$ thiamphenicol,

641 colonies that were noticeably larger (indicative of plasmid integration) were

642 streaked onto onto non-supplemented CDMM to select for uracil prototrophy

643 indicating successful allele exchange. Successful restoration of the WT pyrE allele

644 was confirmed by colony PCR using primers flanking the pyrE locus (P5 and P6,

645 Fig. S2).

$646 S N A P^{C d}$ transcriptional fusions. To construct transcriptional $S N A P^{C d}$ fusions to

647 the spo0A promoter, a 568 bp DNA fragment containing the Spo0A promoter

648 region was PCR-amplified using genomic DNA from strain 630 4 erm and primer

649 pairs CDspo0A_598_Fw/CDspo0A_SNAP_Rev. These fragments were cloned into

650 pFT47 (Pereira et al., 2013) to create pMS463 (Table S3). Plasmid pMS463 was

651 transferred to $630 \Delta e r m$, and congenic $\Delta c s i A$ mutants by conjugation from

652 derivatives of E. coli HB101 (RP4) (Table S1). 
653 SNAP ${ }^{\text {Cd }}$ labelling, fluorescence microscopy and image analysis. Samples of $1 \mathrm{ml}$

654 were withdrawn from SM cultures at the desired times following inoculation, and the

655 cells collected by centrifugation (10 $\mathrm{min}, 4000 \mathrm{xg}$, at $4^{\circ} \mathrm{C}$ ). The cells were washed with

$6561 \mathrm{ml}$ of phosphate-buffered saline (PBS; $137 \mathrm{mM} \mathrm{NaCl}, 10 \mathrm{mM}$ Phosphate, $2.7 \mathrm{mM}$

$657 \mathrm{KCl}, \mathrm{pH} 7.4$ ), and resuspended in $0.1 \mathrm{ml}$ of PBS supplemented with the lipophilic

658 styryl membrane dye $N$-(3-triethylammoniumprpyl)-4-(p-diethylaminophenyl-

659 hexatrienyl) pyridinium dibromide (FM4-64, Molecular Probes, Invitrogen; $10 \mu \mathrm{g} \cdot \mathrm{ml}^{-1}$ )

660 (Pogliano et al., 1999). For SNAP labelling, TMR-Star was added to cells in culture

661 samples inside an anaerobic chamber to a final concentration of $250 \mathrm{nM}$ (New

662 England Biolabs) and the mixture incubated for 30 minutes in the dark. Following

663 labelling, the cells were collected by centrifugation (4000xg for $5 \mathrm{~min}$ ), washed four

664 times with $1 \mathrm{ml}$ of PBS, and finally suspended in $10-20 \mu \mathrm{l}$ of PBS. For phase contrast

665 and fluorescence microscopy, cells were mounted on 1.7\% agarose coated glass

666 slides and observed on a Leica DM6000B microscope equipped with a phase

667 contrast Uplan F1 100x objective and captured with a CCD Andor Ixon camera

668 (Andor Technologies). Images were acquired and analysed using the Metamorph

669 software suite (version 5.8; Universal Imaging) and adjusted and cropped using

670 Photoshop S4. Statistical analysis was carried out using GraphPad Prism (Version

671 7.0; GraphPad Software Inc.). The non-parametric Kolmogorov-Smirnov test (KS-

672 test) was applied to compare distributions obtained from quantifications of the SNAP-

673 TMR signal. The P-value is indicated for all comparisons whose differences were

674 found to be statistically significant. Although the results presented are from a single

675 experiment, all experiments involving quantification of a fluorescence signal were

676 performed independently three times and only results that were considered

677 statistically significant by a KS-test in all three experiments were considered to be

678 statistically relevant. 
679 Preparation of $\boldsymbol{C}$. difficile whole cell extracts and immunoblotting. Whole cell

680 extracts were obtained by withdrawing $20 \mathrm{ml}$ samples from SM or TY cultures of $C$.

681 difficile 6, 8, 10 and 12 hours of after inoculation. The cells were collected by

682 centrifugation ( $4000 \mathrm{xg}$, for $5 \mathrm{~min}$ at $4^{\circ} \mathrm{C}$ ), the cell sediment was washed with

683 phosphate-buffered saline (PBS) and suspended in $1 \mathrm{ml}$ French press buffer (10

$684 \mathrm{mM}$ Tris pH 8.0, $10 \mathrm{mM}$ MgCl2, $0.5 \mathrm{mM}$ EDTA, $0.2 \mathrm{mM} \mathrm{NaCl}, 10 \%$ Glycerol, $1 \mathrm{mM}$

685 PMSF). The cells were lysed using a French pressure cell (18000 lb/in2). Proteins

686 in the extracts were resolved on $12 \%$ SDS-PAGE gels. The anti- $\sigma^{\mathrm{F}}$, anti- $\sigma^{\mathrm{E}}$

687 antibodies (Saujet et al., 2013), anti-Spo0A (Serra et al., 2014) and anti-CsiA were

688 used at a 1:1000 dilution, and an anti-rabbit secondary antibody conjugated to

689 horseradish peroxidase (Sigma) was used at a 1:10000 dilution. The monoclonal

690 anti-TcdA primary antibody (Santa Cruz Biotechnology) were used at a 1:1000

691 dilution, and an anti-mouse secondary antibody conjugated to horseradish

692 peroxidase (Sigma) was used at a 1:2000 dilution. The immunoblots were

693 developed with enhanced chemiluminescence reagents (Amersham Pharmacia

694 Biotech). Images were adjusted and cropped and quantified using ImageJ

695 (http://rsbweb.nih.gov/ij/).

696 Detection of Spo0A phosphorylation using Phos-tag acrylamide gels. Phos-

697 tag acrylamide gels were prepared according to the instructions provided (Wako);

$69810 \%$ acrylamide gels were copolymerized with $25 \mathrm{nM}$ Phos-tag acrylamide and 10

$699 \mathrm{nM} \mathrm{MnCl}$ 2. 20-ml of bacterial cultures were centrifuged at $5,000 \mathrm{~g}$ at $4^{\circ} \mathrm{C}$ for 10

$700 \mathrm{~min}$, and the pellets suspended in $1 \mathrm{ml} 10 \mathrm{mM}$ Tris $\mathrm{pH}$ 8.0. The cells were lysed

701 using a French pressure cell (18000 lb/in2). Samples were stored on ice prior to

702 loading onto Phos-tag acrylamide gels and run at $4^{\circ} \mathrm{C}$. Gels were fixed for $10 \mathrm{~min}$

703 in transfer buffer with $10 \mathrm{mM}$ EDTA and then washed for $10 \mathrm{~min}$ in transfer buffer 
704 without EDTA twice. After transfer to a nitrocellulose membrane, the samples were

705 probed with rabbit polyclonal anti-Spo0A or anti-FliC antibodies at a 1:1000 dilution

706 and an anti-rabbit secondary antibody conjugated to horseradish peroxidase

707 (Sigma) was used at dilution 1:10000. Images were adjusted and cropped and

708 quantified using ImageJ (http://rsbweb.nih.gov/ij/). In order to dephosphorylate

709 Spo0A P, samples were incubated at $100^{\circ} \mathrm{C}$ for $5 \mathrm{~min}$.

710 RNA extraction and RNA-sequencing. RNA for RNA-Seq was extracted from two

711 independent biological replicates of WT and csiA mutant $C$. difficile strains, after 10

712 hours of growth in SM, using a RNeasy Kit (Qiagen). Contaminating genomic DNA

713 was depleted by two DNase treatments (Promega), according to manufacturer's

714 recommendations. DNAse-treated RNA (5 $\mu \mathrm{g})$ was mRNA enriched using a Ribo-

715 Zero Magnetic Kit (Epicentre). After Illumina sequencing the reads were mapped to

716 C. difficile 630 genome using Hisat. Statistical analyses were performed with

717 DESeq2. A gene was considered differentially expressed when the fold change

718 was $>2$ and the adjusted $p$ value was $<0.01$.

719 His $_{6}$-CsiA overproduction purification and polyclonal antibody production. A

720 DNA fragment encoding the csiA gene was generated by PCR from $C$. difficile

$721630 \Delta e r m$ genomic DNA using primers csiA_BamHI_Fw/ csiA_Notl_Rev. The

722 resulting DNA fragment was cut with $\mathrm{BamHI}$ and Notl and cloned between the same

723 sites of pETDuet-1 (Novagen) to produce pDM35. Plasmid pDM35 was introduced

724 into BL21 (DE3) cells and the E. coli strain was grown in autoinduction medium. The

725 cells were then harvested by centrifugation ( $4000 \times \mathrm{g}$, for $10 \mathrm{~min}$, at $\left.4^{\circ} \mathrm{C}\right)$ and the

726 sediment resuspended in lysis buffer (20mM phosphate $\mathrm{pH} 7.4,1 \mathrm{mM}$ PMSF, $10 \mathrm{mM}$

727 Imidazole). The suspension was lysed using a French pressure cell (at $18000 \mathrm{lb} / \mathrm{in}^{2}$ )

728 and the lysate cleared by centrifugation (15000 $\times \mathrm{g}, 30 \mathrm{~min}$ at at $\left.4^{\circ} \mathrm{C}\right)$, and the 
bioRxiv preprint doi: https://doi.org/10.1101/2020.02.25.964569; this version posted February 26, 2020. The copyright holder for this preprint (which was not certified by peer review) is the author/funder. All rights reserved. No reuse allowed without permission.

Martins et al.

729 supernantant was loaded onto a $1 \mathrm{ml}$ Histrap column (Amersham Phamarcia

730 Biotech). The bound protein was eluted with a discontinuous imidazole gradient and

731 the fractions containing $\mathrm{His}_{6}-\mathrm{C}$-SiA were identified by SDS-PAGE. The antibody was

732 produced by Eurogentec (Seraing, Belgium).

733

734 


\section{Acknowledgments}

736 This work was supported by the FCT ("Fundação para a Ciência e a

737 Tecnologia") through program IF (IF/00268/2013/CP1173/CT0006) and award

738 PTDC/BIA-MIC/29293/2017 to MS, by the European Union Marie Sklodowska Curie

739 Innovative Training Networks (contract number 642068 ) to $\mathrm{AOH}$ and by awards

740 5R01Al116895 and 1U01Al124290 from the National Institute of Allergy and

741 Infectious Diseases to SMB. This work was also financially supported by Project

742 LISBOA-01-0145-FEDER-007660 ("Microbiologia Molecular, Estrutural e Celular")

743 funded by FEDER funds through COMPETE2020 - "Programa Operacional

744 Competitividade e Internacionalização" (POCI) and partially supported by project

745 ONEIDA (LISBOA-01-0145-FEDER-016417) co-funded by FEEI - "Fundos

746 Europeus Estruturais e de Investimento" from "Programa Operacional Regional

747 Lisboa 2020". ALM was the recipient of a PhD fellowship (PD/BD/105738/2014)

748 within the scope of the PhD program Molecular Biosciences funded by FCT. DM is

749 the recipient of a PhD fellowship (PD/BD/143148/2019) within the scope of the PhD

750 program INTERFACE funded by FCT. 


\section{References}

753

754

755

756

757

758

759

760

761

762

763

764

765

766

767

768

769

770

771

772

773

774

775

776

777

778

779

780

781

782

783

784

785

786

787

788

789

790

791

792

793

794

795

796

797

798

799

800

801

Abecasis, A.B., M. Serrano, R. Alves, L. Quintais, J.B. Pereira-Leal \& A.O. Henriques, (2013) A genomic signature and the identification of new sporulation genes. $J$ Bacteriol 195: 2101-2115.

Almeida, A., A.L. Mitchell, M. Boland, S.C. Forster, G.B. Gloor, A. Tarkowska, T.D. Lawley \& R.D. Finn, (2019) A new genomic blueprint of the human gut microbiota. Nature 568: 499-504.

Alsaker, K.V., T.R. Spitzer \& E.T. Papoutsakis, (2004) Transcriptional analysis of spo0A overexpression in Clostridium acetobutylicum and its effect on the cell's response to butanol stress. J Bacteriol 186: 1959-1971.

Antunes, A., E. Camiade, M. Monot, E. Courtois, F. Barbut, N.V. Sernova, D.A. Rodionov, I. Martin-Verstraete \& B. Dupuy, (2012) Global transcriptional control by glucose and carbon regulator CcpA in Clostridium difficile. Nucleic Acids Res 40: 1070110718.

Atarashi, K., T. Tanoue, T. Shima, A. Imaoka, T. Kuwahara, Y. Momose, G. Cheng, S. Yamasaki, T. Saito, Y. Ohba, T. Taniguchi, K. Takeda, S. Hori, Ivanov, II, Y. Umesaki, K. Itoh \& K. Honda, (2011) Induction of colonic regulatory T cells by indigenous Clostridium species. Science 331: 337-341.

Ben-Yehuda, S. \& R. Losick, (2002) Asymmetric cell division in B. subtilis involves a spiral-like intermediate of the cytokinetic protein FtsZ. Cell 109: 257-266.

Browne, H.P., S.C. Forster, B.O. Anonye, N. Kumar, B.A. Neville, M.D. Stares, D. Goulding \& T.D. Lawley, (2016) Culturing of 'unculturable' human microbiota reveals novel taxa and extensive sporulation. Nature 533: 543-546.

Carroll, K.C. \& J.G. Bartlett, (2011) Biology of Clostridium difficile: implications for epidemiology and diagnosis. Annu Rev Microbiol 65: 501-521.

Childress, K.O., A.N. Edwards, K.L. Nawrocki, S.E. Anderson, E.C. Woods \& S.M. McBride, (2016) The Phosphotransfer Protein CD1492 Represses Sporulation Initiation in Clostridium difficile. Infect Immun 84: 3434-3444.

Dawson, L.F., E. Valiente, A. Faulds-Pain, E.H. Donahue \& B.W. Wren, (2012) Characterisation of Clostridium difficile biofilm formation, a role for Spo0A. PLoS One 7: e50527.

Deakin, L.J., S. Clare, R.P. Fagan, L.F. Dawson, D.J. Pickard, M.R. West, B.W. Wren, N.F. Fairweather, G. Dougan \& T.D. Lawley, (2012) The Clostridium difficile spo0A gene is a persistence and transmission factor. Infect Immun 80: 2704-2711.

Dembek, M., S.E. Willing, H.A. Hong, S. Hosseini, P.S. Salgado \& S.M. Cutting, (2017) Inducible Expression of spo0A as a Universal Tool for Studying Sporulation in Clostridium difficile. Front Microbiol 8: 1793.

Dineen, S.S., A.C. Villapakkam, J.T. Nordman \& A.L. Sonenshein, (2007) Repression of Clostridium difficile toxin gene expression by CodY. Mol Microbiol 66: 206-219.

Driks, A. \& P. Eichenberger, (2016) The Spore Coat. Microbiol Spectr 4.

Dworkin, J. \& R. Losick, (2005) Developmental commitment in a bacterium. Cell 121: 401-409.

Edwards, A.N., B.R. Anjuwon-Foster \& S.M. McBride, (2019) RstA Is a Major Regulator of Clostridioides difficile Toxin Production and Motility. mBio 10.

Edwards, A.N., K.L. Nawrocki \& S.M. McBride, (2014) Conserved oligopeptide permeases modulate sporulation initiation in Clostridium difficile. Infect Immun 82: 4276-4291.

Edwards, A.N., R. Tamayo \& S.M. McBride, (2016) A novel regulator controls Clostridium difficile sporulation, motility and toxin production. Mol Microbiol 100: 954-971. 
Errington, J., (2003) Regulation of endospore formation in Bacillus subtilis. Nat Rev Microbiol 1: 117-126.

Fimlaid, K.A., J.P. Bond, K.C. Schutz, E.E. Putnam, J.M. Leung, T.D. Lawley \& A. Shen, (2013) Global analysis of the sporulation pathway of Clostridium difficile. PLoS Genet 9: e1003660.

Fujita, M., J.E. Gonzalez-Pastor \& R. Losick, (2005) High- and low-threshold genes in the Spo0A regulon of Bacillus subtilis. J Bacteriol 187: 1357-1368.

Fujita, M. \& R. Losick, (2005) Evidence that entry into sporulation in Bacillus subtilis is governed by a gradual increase in the level and activity of the master regulator Spo0A. Genes Dev 19: 2236-2244.

Fujita, M. \& Y. Sadaie, (1998) Feedback loops involving Spo0A and AbrB in in vitro transcription of the genes involved in the initiation of sporulation in Bacillus subtilis. J Biochem 124: 98-104.

Galperin, M.Y., S.L. Mekhedov, P. Puigbo, S. Smirnov, Y.I. Wolf \& D.J. Rigden, (2012) Genomic determinants of sporulation in Bacilli and Clostridia: towards the minimal set of sporulation-specific genes. Environ Microbiol 14: 2870-2890.

Girinathan, B.P., J. Ou, B. Dupuy \& R. Govind, (2018) Pleiotropic roles of Clostridium difficile sin locus. PLoS Pathog 14: e1006940.

Heap, J.T., O.J. Pennington, S.T. Cartman, G.P. Carter \& N.P. Minton, (2007) The ClosTron: a universal gene knock-out system for the genus Clostridium. $J$ Microbiol Methods 70: 452-464.

Henriques, A.O. \& C.P. Moran, Jr., (2007) Structure, assembly, and function of the spore surface layers. Annu Rev Microbiol 61: 555-588.

Higgins, D. \& J. Dworkin, (2012) Recent progress in Bacillus subtilis sporulation. FEMS Microbiol Rev 36: 131-148.

Hussain, H.A., A.P. Roberts \& P. Mullany, (2005) Generation of an erythromycin-sensitive derivative of Clostridium difficile strain 630 (630Deltaerm) and demonstration that the conjugative transposon Tn916DeltaE enters the genome of this strain at multiple sites. J Med Microbiol 54: 137-141.

Jiang, M., W. Shao, M. Perego \& J.A. Hoch, (2000) Multiple histidine kinases regulate entry into stationary phase and sporulation in Bacillus subtilis. Mol Microbiol 38: 535-542.

Karasawa, T., S. Ikoma, K. Yamakawa \& S. Nakamura, (1995) A defined growth medium for Clostridium difficile. Microbiology 141 ( Pt 2): 371-375.

Khvorova, A., L. Zhang, M.L. Higgins \& P.J. Piggot, (1998) The spoIIE locus is involved in the Spo0A-dependent switch in the location of FtsZ rings in Bacillus subtilis. $J$ Bacteriol 180: 1256-1260.

Koide, A. \& J.A. Hoch, (1994) Identification of a second oligopeptide transport system in Bacillus subtilis and determination of its role in sporulation. Mol Microbiol 13: 417426.

Levin, P.A. \& R. Losick, (1996) Transcription factor Spo0A switches the localization of the cell division protein FtsZ from a medial to a bipolar pattern in Bacillus subtilis. Genes Dev 10: 478-488.

Lewis, R.J., J.A. Brannigan, K. Muchova, I. Barak \& A.J. Wilkinson, (1999) Phosphorylated aspartate in the structure of a response regulator protein. $\mathrm{J} \mathrm{Mol} \mathrm{Biol}$ 294: 9-15.

McKenney, P.T., A. Driks \& P. Eichenberger, (2013) The Bacillus subtilis endospore: assembly and functions of the multilayered coat. Nat Rev Microbiol 11: 33-44.

Molle, V., M. Fujita, S.T. Jensen, P. Eichenberger, J.E. Gonzalez-Pastor, J.S. Liu \& R. Losick, (2003) The Spo0A regulon of Bacillus subtilis. Mol Microbiol 50: 16831701. 
Narula, J., S.N. Devi, M. Fujita \& O.A. Igoshin, (2012) Ultrasensitivity of the Bacillus subtilis sporulation decision. Proc Natl Acad Sci U S A 109: E3513-3522.

Nawrocki, K.L., A.N. Edwards, N. Daou, L. Bouillaut \& S.M. McBride, (2016) CodYDependent Regulation of Sporulation in Clostridium difficile. J Bacteriol 198: 2113-2130.

Ng, Y.K., M. Ehsaan, S. Philip, M.M. Collery, C. Janoir, A. Collignon, S.T. Cartman \& N.P. Minton, (2013) Expanding the repertoire of gene tools for precise manipulation of the Clostridium difficile genome: allelic exchange using pyrE alleles. PLoS One 8: e56051.

Paredes-Sabja, D., A. Shen \& J.A. Sorg, (2014) Clostridium difficile spore biology: sporulation, germination, and spore structural proteins. Trends Microbiol.

Perego, M., C.F. Higgins, S.R. Pearce, M.P. Gallagher \& J.A. Hoch, (1991) The oligopeptide transport system of Bacillus subtilis plays a role in the initiation of sporulation. Mol Microbiol 5: 173-185.

Pereira, F.C., L. Saujet, A.R. Tomé, M. Serrano, M. Monot, E. Couture-Tosi, I. MartinVerstraete, B. Dupuy \& A.O. Henriques, (2013) The spore differentiation pathway in the enteric pathogen Clostridium difficile. PLoS Genet.

Pettit, L.J., H.P. Browne, L. Yu, W.K. Smits, R.P. Fagan, L. Barquist, M.J. Martin, D. Goulding, S.H. Duncan, H.J. Flint, G. Dougan, J.S. Choudhary \& T.D. Lawley, (2014) Functional genomics reveals that Clostridium difficile Spo0A coordinates sporulation, virulence and metabolism. BMC Genomics 15: 160.

Piggot, P.J. \& D.W. Hilbert, (2004) Sporulation of Bacillus subtilis. Curr Opin Microbiol 7: 579-586.

Pogliano, J., N. Osborne, M.D. Sharp, A. Abanes-De Mello, A. Perez, Y.L. Sun \& K. Pogliano, (1999) A vital stain for studying membrane dynamics in bacteria: a novel mechanism controlling septation during Bacillus subtilis sporulation. Mol Microbiol 31: 1149-1159.

Putnam, E.E., A.M. Nock, T.D. Lawley \& A. Shen, (2013) SpoIVA and SipL are Clostridium difficile spore morphogenetic proteins. J Bacteriol 195: 1214-1225.

Rosenbusch, K.E., D. Bakker, E.J. Kuijper \& W.K. Smits, (2012) C. difficile 630Deltaerm Spo0A regulates sporulation, but does not contribute to toxin production, by direct high-affinity binding to target DNA. PLoS One 7: e48608.

Saujet, L., M. Monot, B. Dupuy, O. Soutourina \& I. Martin-Verstraete, (2011) The key sigma factor of transition phase, SigH, controls sporulation, metabolism, and virulence factor expression in Clostridium difficile. J Bacteriol 193: 3186-3196.

Saujet, L., F.C. Pereira, M. Serrano, O. Soutourina, M. Monot, P.V. Shelyakin, M.S. Gelfand, B. Dupuy, A.O. Henriques \& I. Martin-Verstraete, (2013) Genome-wide analysis of cell type-specific gene expression during spore formation in Clostridium difficile. PLoS Genet.

Serra, C.R., A.M. Earl, T.M. Barbosa, R. Kolter \& A.O. Henriques, (2014) Sporulation during growth in a gut isolate of Bacillus subtilis. J Bacteriol 196: 4184-4196.

Sonenshein, A.L., (2000) Control of sporulation initiation in Bacillus subtilis. Curr Opin Microbiol 3: 561-566.

Steiner, E., A.E. Dago, D.I. Young, J.T. Heap, N.P. Minton, J.A. Hoch \& M. Young, (2011) Multiple orphan histidine kinases interact directly with Spo0A to control the initiation of endospore formation in Clostridium acetobutylicum. Mol Microbiol 80: 641-654.

Stewart, G.C., (2015) The Exosporium Layer of Bacterial Spores: a Connection to the Environment and the Infected Host. Microbiol Mol Biol Rev 79: 437-457. 
Traag, B.A., A. Pugliese, J.A. Eisen \& R. Losick, (2013) Gene conservation among endospore-forming bacteria reveals additional sporulation genes in Bacillus subtilis. J Bacteriol 195: 253-260.

Underwood, S., S. Guan, V. Vijayasubhash, S.D. Baines, L. Graham, R.J. Lewis, M.H. Wilcox \& K. Stephenson, (2009) Characterization of the sporulation initiation pathway of Clostridium difficile and its role in toxin production. $J$ Bacteriol 191: 7296-7305.

Vishnoi, M., J. Narula, S.N. Devi, H.A. Dao, O.A. Igoshin \& M. Fujita, (2013) Triggering sporulation in Bacillus subtilis with artificial two-component systems reveals the importance of proper Spo0A activation dynamics. Mol Microbiol 90: 181-194.

Wilson, K.H., M.J. Kennedy \& F.R. Fekety, (1982) Use of sodium taurocholate to enhance spore recovery on a medium selective for Clostridium difficile. J Clin Microbiol 15: 443-446.

Winkelman, J.T., K.M. Blair \& D.B. Kearns, (2009) RemA (YlzA) and RemB (YaaB) regulate extracellular matrix operon expression and biofilm formation in Bacillus subtilis. J Bacteriol 191: 3981-3991.

Winkelman, J.T., A.C. Bree, A.R. Bate, P. Eichenberger, R.L. Gourse \& D.B. Kearns, (2013) RemA is a DNA-binding protein that activates biofilm matrix gene expression in Bacillus subtilis. Mol Microbiol 88: 984-997.

Worner, K., H. Szurmant, C. Chiang \& J.A. Hoch, (2006) Phosphorylation and functional analysis of the sporulation initiation factor Spo0A from Clostridium botulinum. Mol Microbiol 59: 1000-1012.

Yasugi, M., D. Okuzaki, R. Kuwana, H. Takamatsu, M. Fujita, M.R. Sarker \& M. Miyake, (2016) Transcriptional Profile during Deoxycholate-Induced Sporulation in a Clostridium perfringens Isolate Causing Foodborne Illness. Appl Environ Microbiol 82: 2929-2942.

Zhu, D., J.A. Sorg \& X. Sun, (2018) Clostridioides difficile Biology: Sporulation, Germination, and Corresponding Therapies for C. difficile Infection. Front Cell Infect Microbiol 8: 29. 


\section{Figure Legends}

933 Figure 1. Genomic signature of sporulation. A: main stages of sporulation

934 starting with asymmetric division of the rod-shaped cell and the production of the

935 larger mother cell and the smaller forespore (the developing spore) through the

936 development of full spore refractivity, until the release of the spore into the

937 environment. The onset of sporulation is controlled by phosphorylation of Spo0A.

938 After asymmetric division, the forespore and the mother cell compartments follow

939 different lines of gene expression. B: The inner circle contains the signature

940 defined as those genes present in $90 \%$ of sporulating bacteria and in no more than

$94110 \%$ of the remaining bacterial species (Abecasis et al., 2013). The outer circle has

942 the remaining genes identified in a genomic signature of sporulation within the

943 human intestinal microbiome (Browne et al., 2016). Both signatures are enriched

944 with known sporulation-associated genes involved in spore morphogenesis and

945 germination. Genes not specifically associated with a sporulation stage or

946 uncharacterized genes are shown inside the circles. The positions of the genes are

947 shown in degrees in the $C$. difficile 630 chromosome. The csiA gene (CD25890) is

948 a signature gene not previously characterized (blue arrow). C: schematic

949 representation of the csiA (CD25890) region of the $C$. difficile $630 \Delta \mathrm{erm}$

950 chromosome. The $\Delta c s i A$ in-frame deletion removed codons 5 through 291 of the

951 293-codons-long csiA gene.

952 Figure 2. Sporulation dynamics of the $\Delta c s i A$ mutant. A: Cells were grown in

953 liquid SM and the titer of heat resistant spores (filled symbols) and total viable cells

954 (open symbols) measured 12, 24, 48 and 72 hours following inoculation. WT,

955 triangles; $\Delta c \operatorname{csi}$ mutant, circles; $c \operatorname{csi}^{C}$ (complementation strain), squares. The date 
956 in the graph represent the mean of three independent experiments (see also Table

957 1). Asterisks indicate statistical significance determined with a two-way ANOVA

958 (ns, no significant; ${ }^{* * *} p<0.0001$ ). B: Samples of an SM liquid culture of the WT

959 strain were collected at 8, 10, 12, 14, 16, 18 and 20 hours after inoculation, stained

960 with the membrane dye FM4-64 and examined by phase contrast or fluorescent

961 microscopy. The panels illustrate the sequence of the stages in sporulation. C:

962 Quantification of the percentage of cells in the morphological classes represented

963 in B (a to $f$ ), relative to the total viable cell population, for the WT (red) and $\Delta c s i A$

964 mutant (blue) at the indicated times following inoculation in liquid SM. The data

965 represent the mean \pm SD of three independent experiments. The total number of

966 cells scored $(n)$ is indicated in each panel. D: Time, in hours, when at least $10 \%$ of

967 WT or $\triangle c s i A$ population reached the indicated stages of sporulation. The top

968 columns shows phase-bright, phase-grey spores or free spores (classes $d$, e and

$969 f)$, the middle columns engulfment completion (c), and the bottom columns

970 asymmetric septation (a).

971 Figure 3. Accumulation of CsiA during growth and sporulation. The wild type

972 strain (WT), the $\triangle c \operatorname{csi} A$ mutant, the complementation strain $\left(\operatorname{csi} A^{\mathrm{C}}\right)(\mathbf{A})$ and the

973 spoOA mutant (B) were grown in SM and samples were collected at 6, 8, 10 and 12

974 hours after inoculation for Western blot analysis using anti-CsiA ( ${ }^{*}$ cross-reactive

975 species). The position of molecular weight markers (in $\mathrm{kDa}$ ) is indicated on the left

976 side of the panels.

977 Figure 4. Increased expression of spo0A in the $\triangle$ csiA mutant. A: Microscopy

978 analysis of $C$. difficile cells carrying a $\mathrm{P}_{\text {spoOA }}-S N A P^{C d}$ transcriptional fusion in the

979 WT and congenic $\Delta c$ csiA mutant. The cells were collected after $10 \mathrm{~h}$ of growth in

980 SM, stained with TMR-Star, and examined by fluorescence microscopy to monitor 
981 SNAP production. The panels are representative of the expression patterns

982 observed. The numbers refer to the percentage of cells showing SNAP

983 fluorescence. Data shown are from one experiment, representative of at least three

984 independent experiments. Scale bar, $1 \mu \mathrm{m}$. B: Quantitative analysis of the

985 fluorescence intensity (FI.) for single cells with no signs of sporulation $(n=100$

986 cells) of the two strains in A. Data shown are from one experiment, representative

987 of at least three independent experiments. The numbers in the legend represent

988 the mean and the SD of fluorescence intensity. ${ }^{* * *}, p<0.001$. C: Samples were

989 collected from the wild type strain (WT), the $\Delta c s i A$ mutant and the

990 complementation strain $\left(\operatorname{csi}^{\mathrm{C}}\right)$ grown in liquid SM, at the indicated times after

991 inoculation. Extracts were prepared and proteins $(15 \mu \mathrm{g})$ resolved by SDS-PAGE

992 and subjected to immunobloting using an anti-Spo0A antibody. The position of

993 molecular weight markers (in $\mathrm{kDa}$ ) is indicated on the left side of the panels.

994 Figure 5. Phosphorylation of Spo0A in the $\Delta c s i A$ mutant. A: Samples were

995 collected from the WT and the $\triangle c$ csiA mutant grown in liquid SM, at the indicated

996 times after inoculation. Extracts were prepared and proteins $(15 \mu \mathrm{g})$ resolved by

997 Phos-tag SDS-PAGE and subjected to immunobloting using an anti-Spo0A

998 antibody. In the bottom panel the same extracts were loaded in a SDS-PAGE and

999 subjected to immunoblotting using an anti- FliC antibody, as a loading control. The

1000 position of molecular weight markers (in $\mathrm{kDa}$ ) is indicated on the left side of the

1001 panels. B and D: The ratio of Spo0A P to Spo0A was assessed with Image J

1002 software and represented for the WT and the $\Delta c s i A$ mutant at the indicated times

1003 (in hours) after inoculation in liquid SM. All data represent the means \pm SD from

1004 three independent experiments. Asterisks indicate statistical significance

1005 determined by two-tailed Student t-test (ns, no significant; ${ }^{* * * *} p<0.0001,{ }^{* * *} p<$ 
1006

1007

1008

1009

1010

1011

1012

1013

1014

1015

1016

1017

1018

1019

1020

1021

1022

1023

1024

1025

1026

1027

1028

1029

1030

0.001). C: Extracts were prepared from liquid SM cultures of the $\mathrm{P}_{\text {tet }}$ Spo0A and $\triangle c s i A \mathrm{P}_{\text {tet }}$ spoOA strains grown in the presence $(50 \mathrm{nM})$ or in the absence of anhydrotetracycline, 8 hours after inoculation. Proteins $(15 \mu \mathrm{g})$ were resolved by Phos-tag SDS-PAGE and subject to immunoblotting using an anti-Spo0A antibody. In $\mathbf{A}$ and $\mathbf{C}$ : The faster migrating bands (black arrows) show the unphosphorylated form of Spo0A (Spo0A), and the slower migrating bands indicate the phosphorylated form of Spo0A (Spo0A P; red arrows). The samples heated at $100^{\circ} \mathrm{C}$ for 5 min were loaded as a control for the position of unphosphorylated Spo0A.

Figure 6. Increased sporulation-specific gene expression in the $\Delta c s i A$

mutant. A: Microscopy analysis of $C$. difficile cells carrying transcriptional fusions of the sigF, sigE, gpr and spollIA promotors to SNAP in the WT and in the $\triangle c s i A$ mutant. The cells were collected after $12 \mathrm{~h}$ of growth in liquid SM, stained with TMR-Star and the membrane dye MTG, and examined by fluorescence microscopy to monitor SNAP production. The merged image shows the overlap between the TMR-Star (red) and MTG (green) channels. The images are representative of the expression patterns observed. The numbers refer to the percentage of cells showing SNAP fluorescence. Data shown are from one experiment, representative of at least three independent experiments. Scale bar, 1 $\mu \mathrm{m}$. B: Quantitative analysis of the fluorescence intensity (in arbitrary units, $A U$ ) of the reporter strains for sigF, sigE, gpr and spolllA transcription, as indicated. The numbers in the legend represent the average and the standard deviation of fluorescence intensity for the cells considered ( $n=50$ cells). ${ }^{* \star *}, p<0.0001$. C:

Extracts were prepared from liquid SM cultures of the WT, $\Delta c s i A$ mutant and the complementation strain $\left(c \operatorname{si}^{C}\right)$, grown, at the indicated times after inoculation. 
1031 Proteins $(15 \mu \mathrm{g})$ were resolved by SDS-PAGE (12\%) and subject to

1032 immunoblotting with anti- $\sigma^{\mathrm{E}}$ and anti- $\sigma^{\mathrm{F}}$ antibodies. The position of molecular

1033 weight markers (in $\mathrm{kDa}$ ) is indicated on the left side of the panels. D: measurement

1034 of the increase in Spo0A activity as a function of aTc using a $\mathrm{P}_{\text {sigF- }}$ SNAP (light

1035 grey) or $\mathrm{P}_{\text {sige }}$ SNAP (dark grey) reporter and the formation of asymmetric septa.

1036 Asterisks indicate statistical significance determined by two-way ANOVA (ns, no

1037 significant, $\left.{ }^{* *} p<0.001,{ }^{*} p<0.01\right)$.

1038 Figure 7. Model for the function of the csiA gene. A: Functional classes of the

1039 genes that are up-regulated in the $\triangle c s i A$ mutant based on RNA seq data (left; the

1040 number represent the percentage of each functional class) and the up-regulated

1041 sporulation genes in the indicated cell type-specific regulons (right; the numbers

1042 represent the percentage of each of the regulons). See also Table 3 B. Model for

1043 the function of the csiA gene in controlling sporulation initiation in $C$. difficile. 
1047 Table 1 - Sporulation efficiency of the $\Delta$ csiA mutant. The total viable cell count and the spore titer was determined $12,24,48$ and 72 hours following inoculation into sporulation medium. The heat resistant spore count by determining the CFU/ml before and after

\begin{tabular}{|c|c|c|c|c|c|c|c|c|}
\hline & $12 \mathrm{~h}$ & & $24 \mathrm{~h}$ & & $48 \mathrm{~h}$ & & $72 \mathrm{~h}$ & \\
\hline & Total viable cells & Spore titer & Total viable cells & Spore titer & Total viable cells & Spore titer & Total viable cells & Spore titer \\
\hline WT & $1.6 \times 10^{8} \pm 7.4 \times 10^{7}$ & $7.5 \times 10^{3} \pm 9.8 \times 10^{2}$ & $1.7 \times 10^{8} \pm 8.7 \times 10^{7}$ & $1.0 \times 10^{4} \pm 1.2 \times 10^{3}$ & $8.5 \times 10^{7} \pm 1.1 \times 10^{7}$ & $1.3 \times 10^{5} \pm 5.1 \times 10^{4}$ & $1.0 \times 10^{7} \pm 1.3 \times 10^{6}$ & $1.7 \times 10^{5} \pm 5.8 \times 10^{4}$ \\
\hline $\operatorname{csi} A^{C}$ & $1.6 \times 10^{8} \pm 7.1 \times 10^{6}$ & $1.8 \times 10^{4} \pm 7.8 \times 10^{3}$ & $2.3 \times 10^{8} \pm 1.4 \times 10^{8}$ & $1.5 \times 10^{4} \pm 6.8 \times 10^{3}$ & $3.0 \times 10^{7} \pm 1.7 \times 10^{7}$ & $7.8 \times 10^{4} \pm 2.0 \times 10^{4}$ & $1.0 \times 10^{7} \pm 5.3 \times 10^{6}$ & $6.0 \times 10^{4} \pm 2.0 \times 10^{4}$ \\
\hline
\end{tabular}

1049 incubation at $70^{\circ} \mathrm{C}$ for $10 \mathrm{~min}$. The results shown are averages and standard deviations for three biological replicates. 
1052 Table 2 - Sporulation efficiency of the Ptet-spo0A alleles. The total viable cell count and the spore titer was determined 24 hours 1053

1054

1055

1056

1057

\section{following inoculation into sporulation medium supplemented with $50 \mathrm{nM}$ of anhydrotetracycline. The heat resistant spore count by}

determining the cfu/mL obtained after treatment at $70^{\circ} \mathrm{C}$. The results shown are averages and standard deviations for three biological replicates.

\begin{tabular}{|c|c|c|}
\hline & $24 \mathrm{~h}$ & 1058 \\
\hline & Total viable cells & Spore titer 059 \\
\hline WT $\mathrm{P}_{\text {tet }}-\mathrm{SpoOA}$ & $2.1 \times 10^{7} \pm 1.3 \times 10^{6}$ & $6.8 \times 10^{6} \pm 1.36 P 0^{5}$ \\
\hline$\triangle c s i A \mathrm{P}_{\text {tet- }} s p o 0 A$ & $2.2 \times 10^{7} \pm 1.6 \times 10^{6}$ & $7.6 \times 10^{6} \pm 1.96 \times 10^{5}$ \\
\hline
\end{tabular}


Martins et al. - Figure 1

A

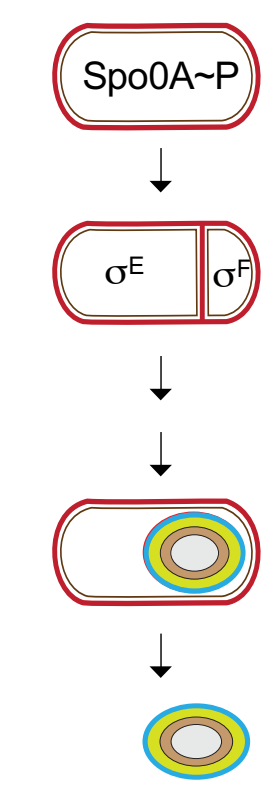

C

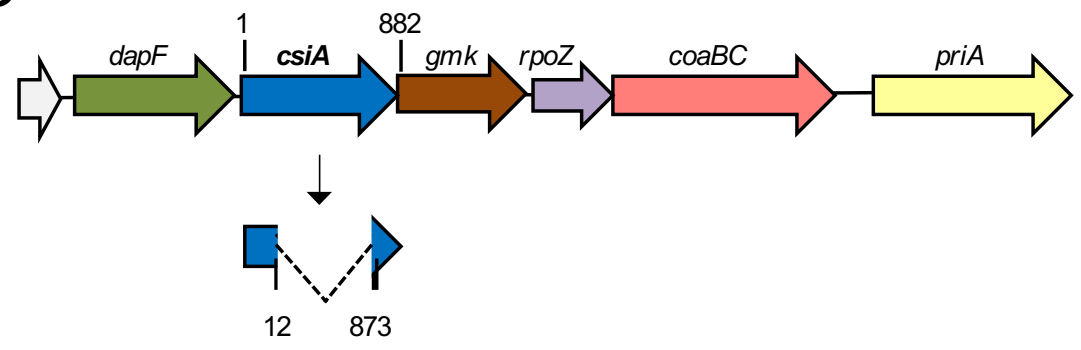

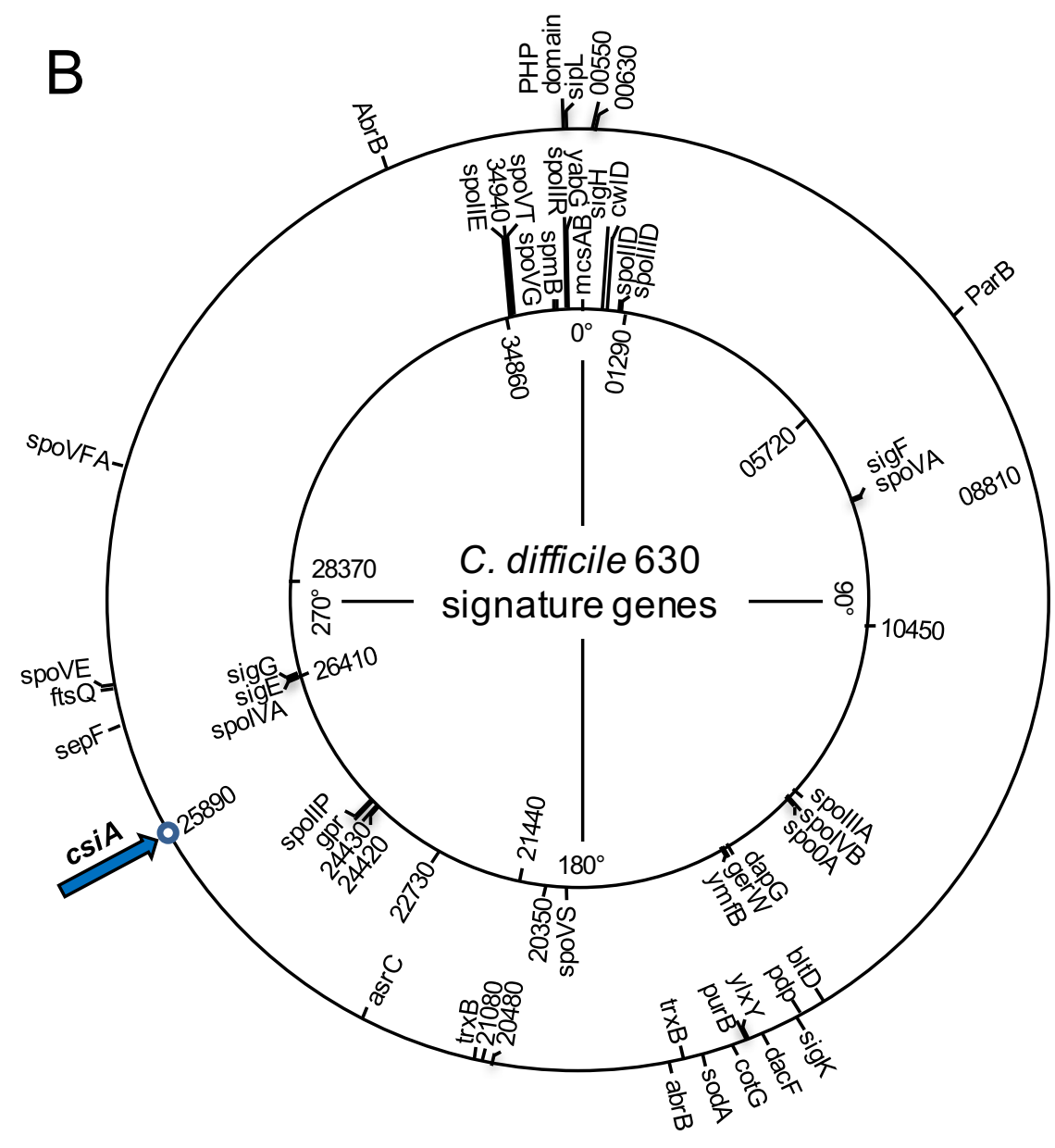



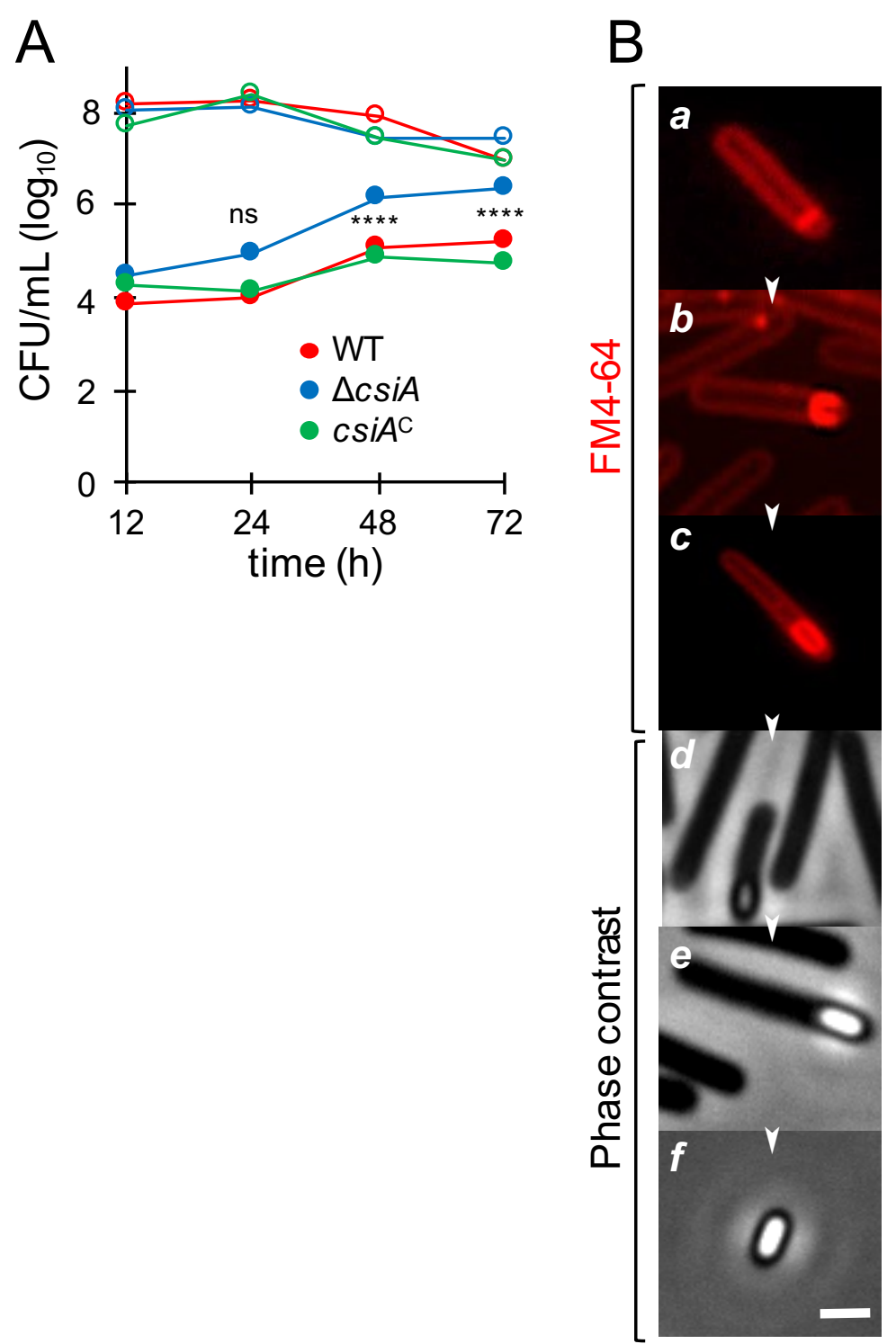

C
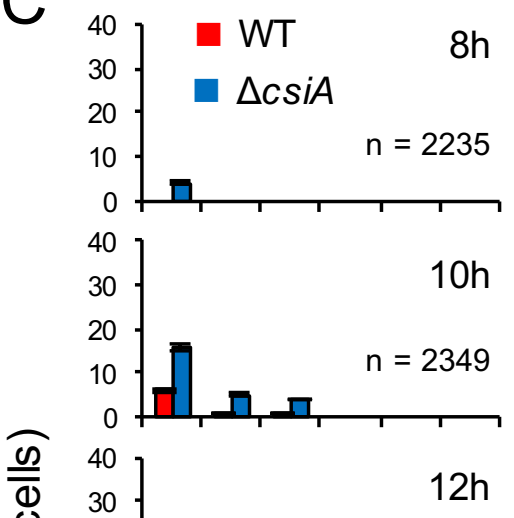

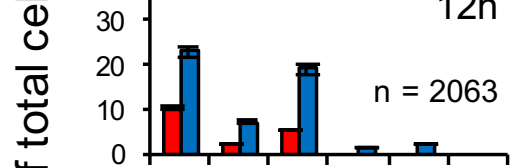

苑

40

อ̊ 30

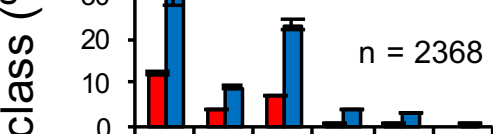

ᄃ $4016 \mathrm{~h}$

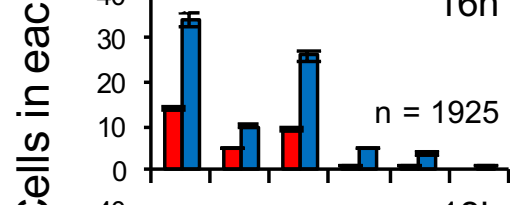

40 18h
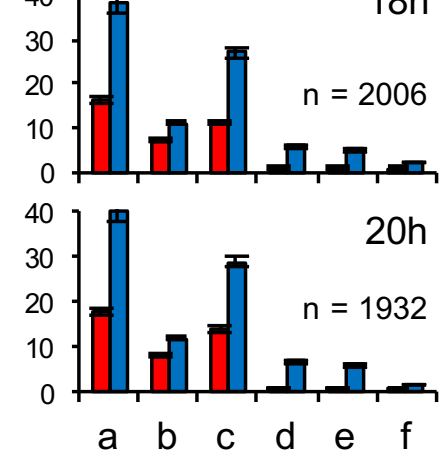

D

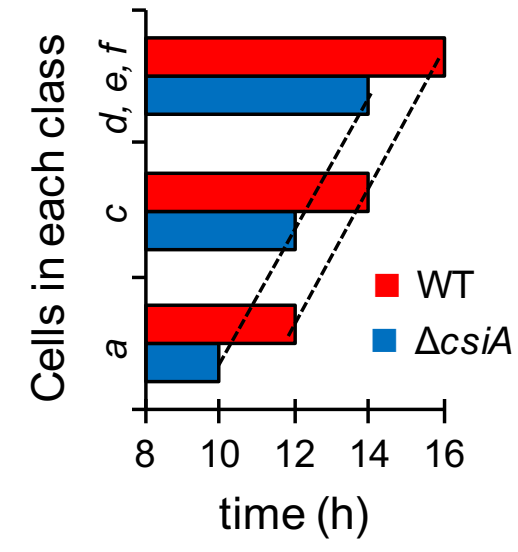



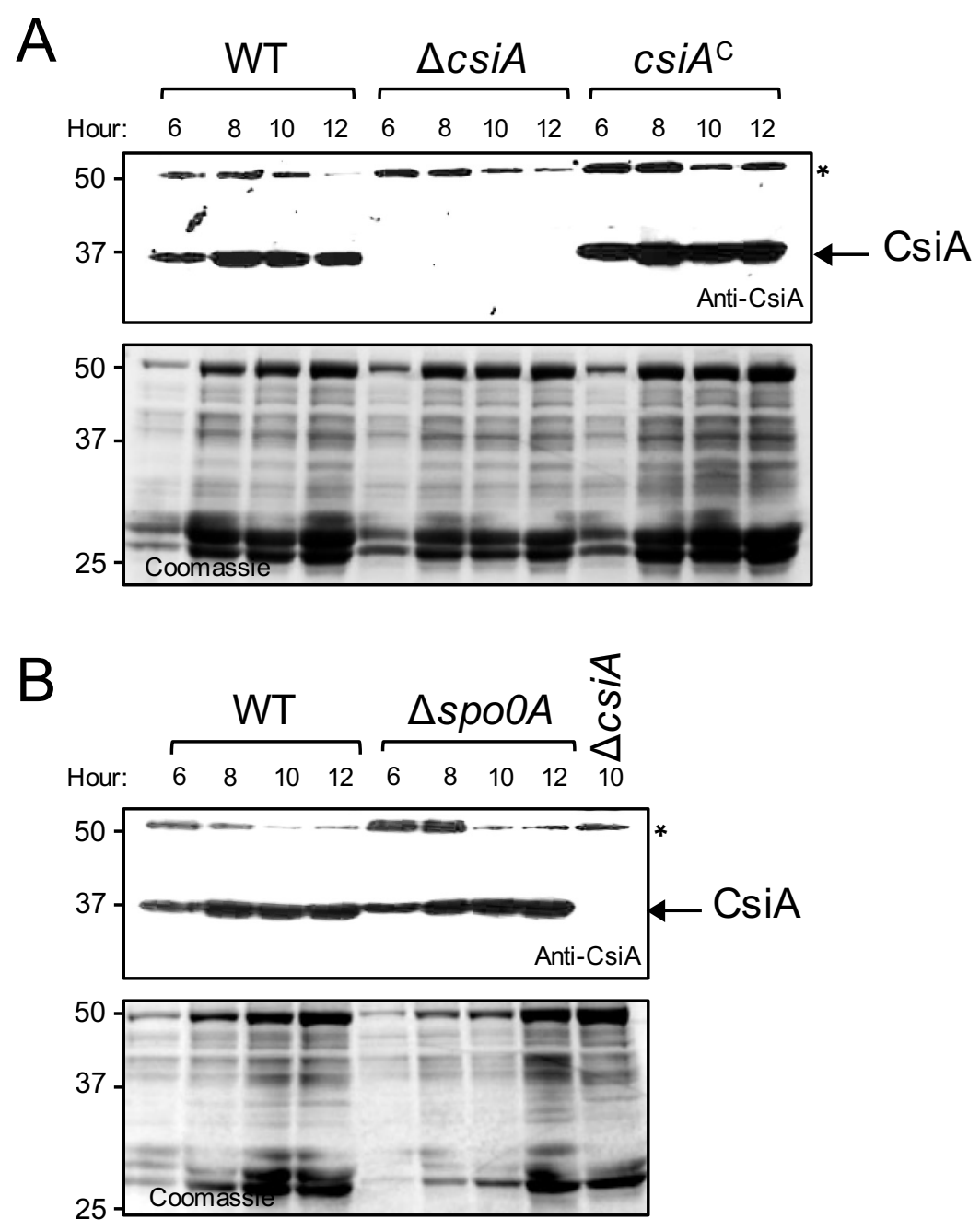

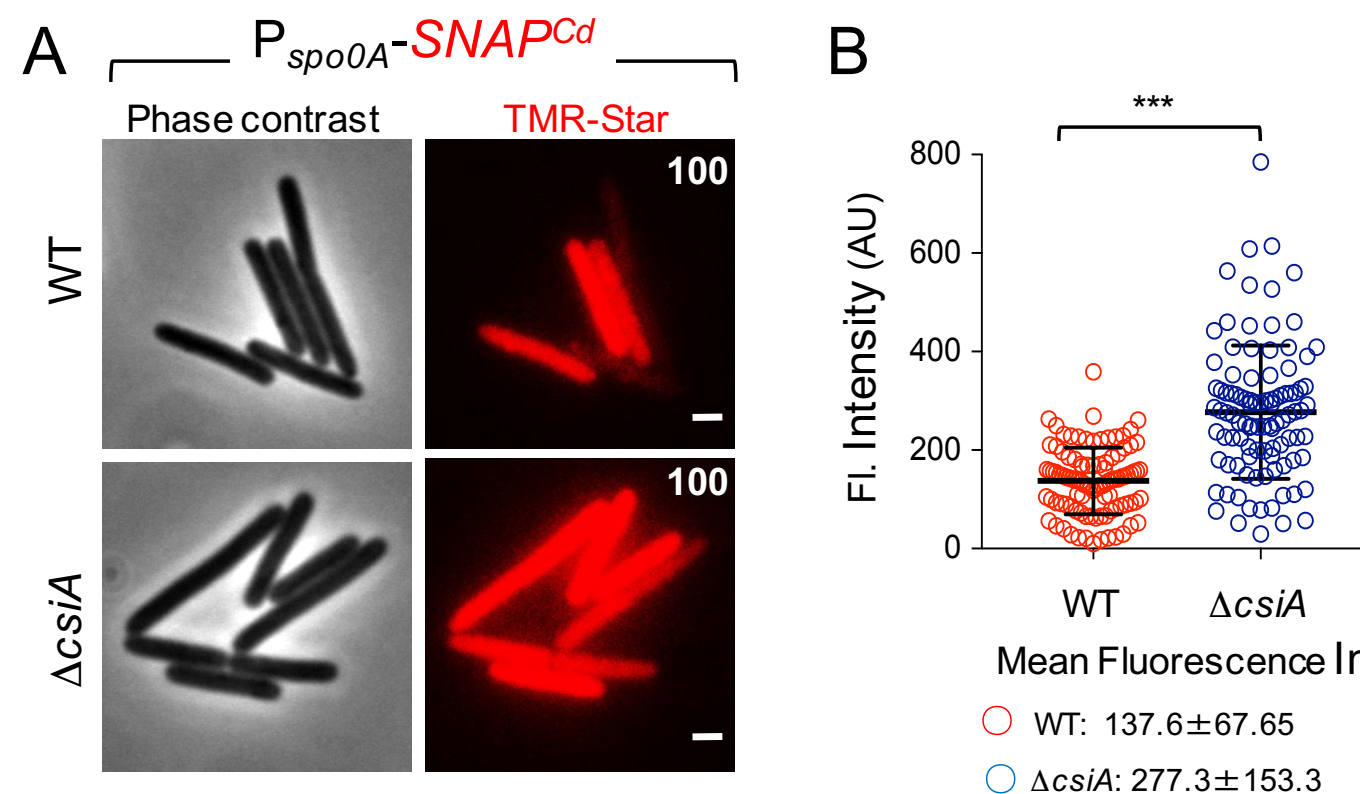

Mean Fluorescence Intensity (AU):

WT: $137.6 \pm 67.65$

$\triangle c s i A: 277.3 \pm 153.3$

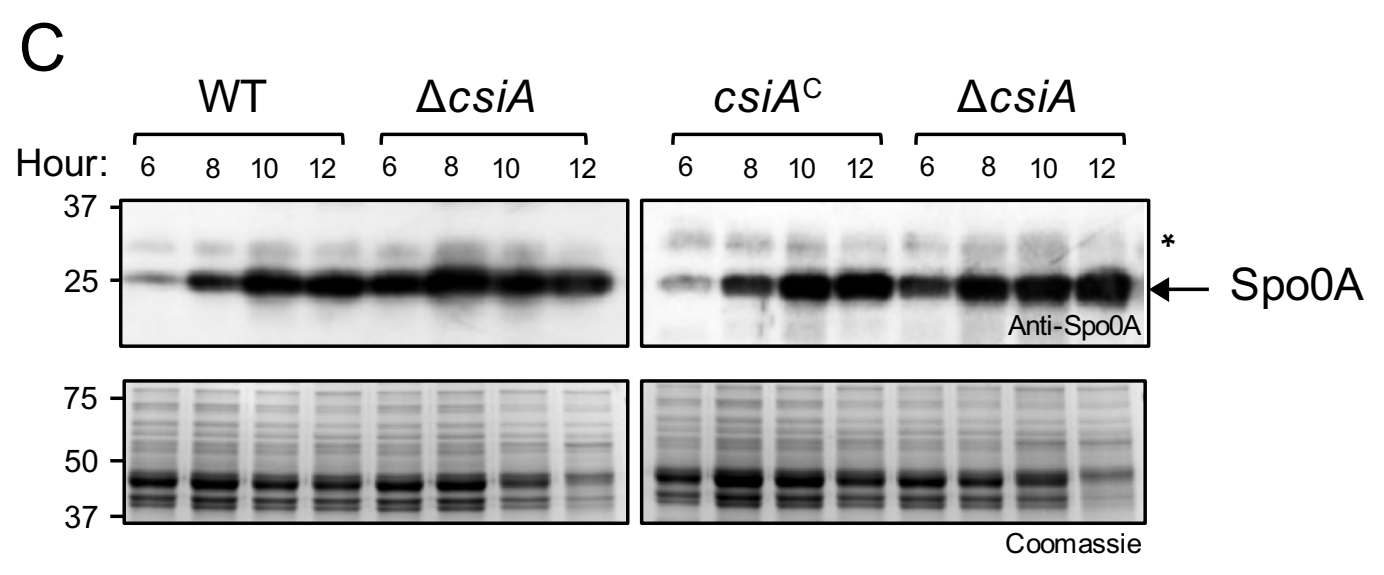




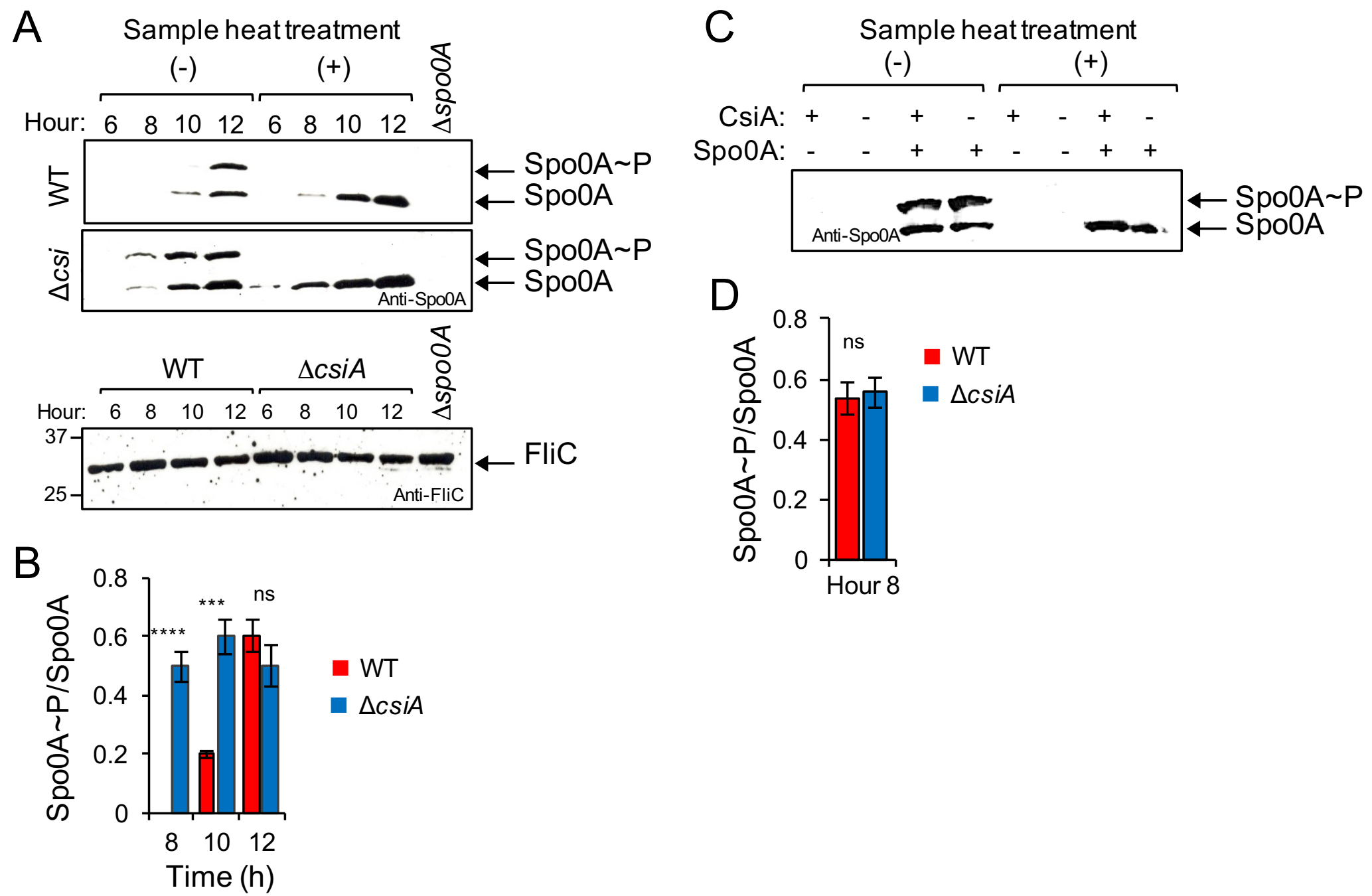




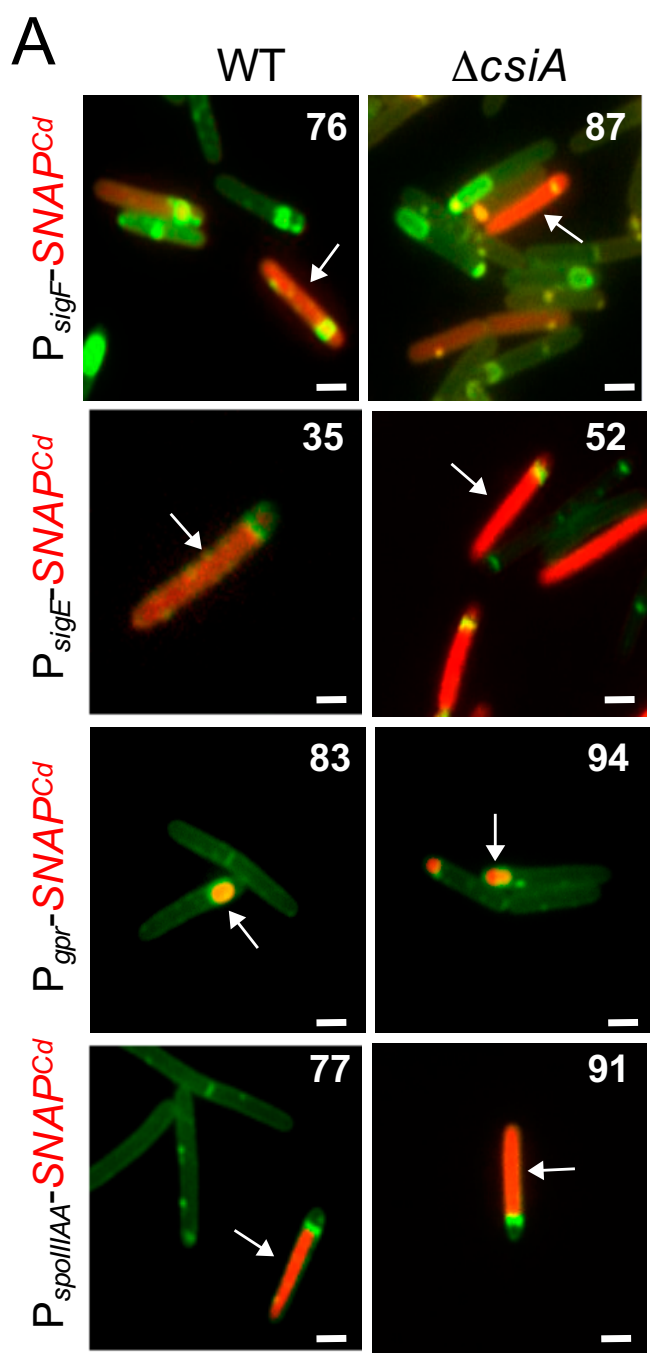

B
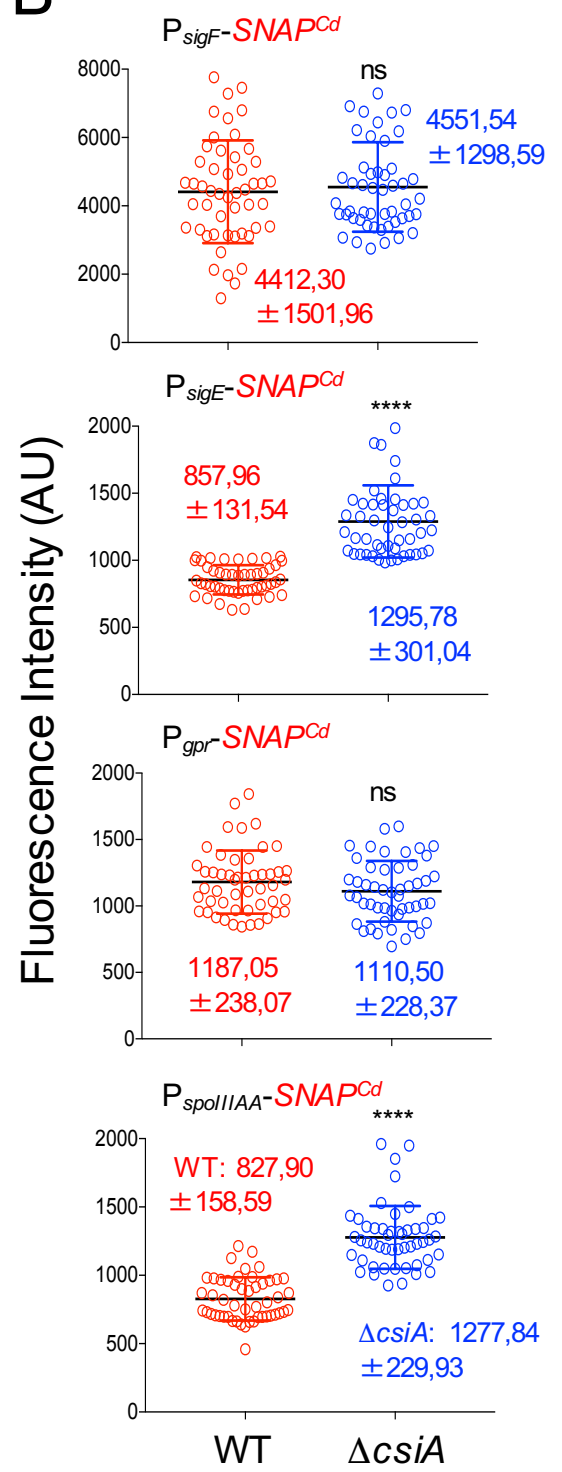

C
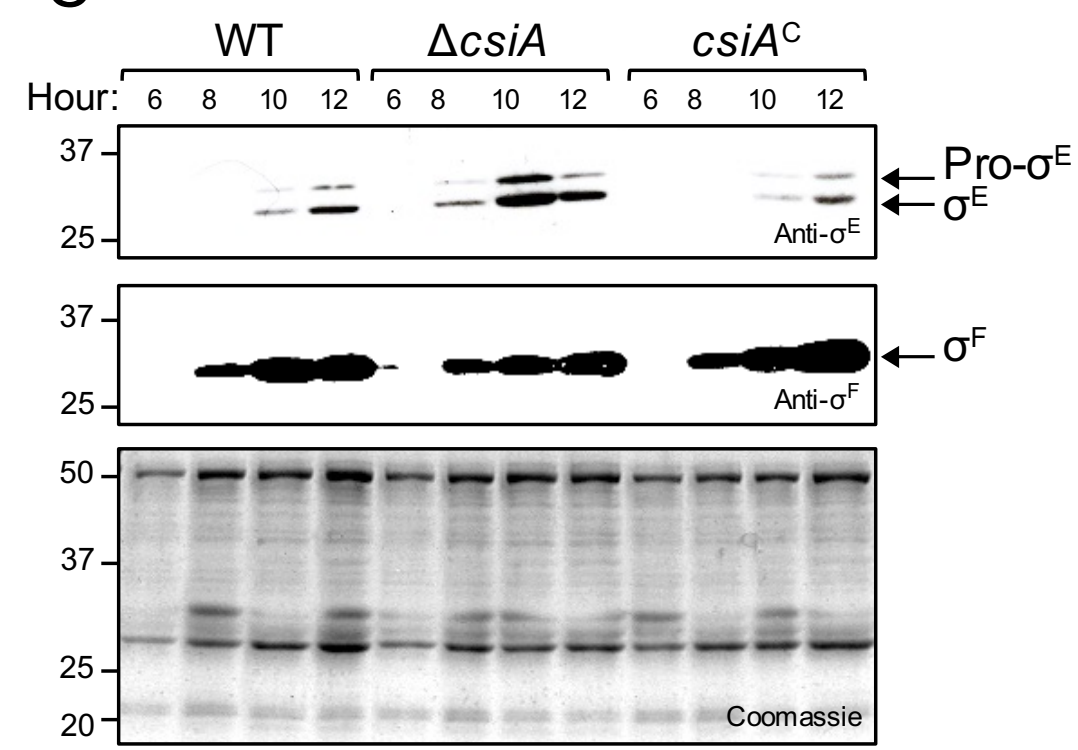

D $\mathrm{P}_{\text {tet }}$ SpoOA

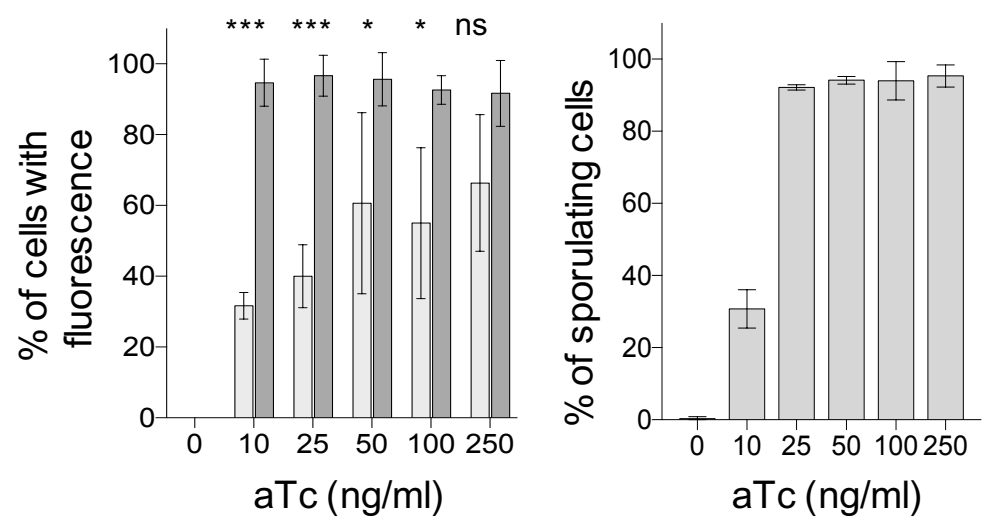

SNAPCd fusions: $\square \mathrm{P}_{\text {sigf }} \square \mathrm{P}_{\text {sigE }}$ 


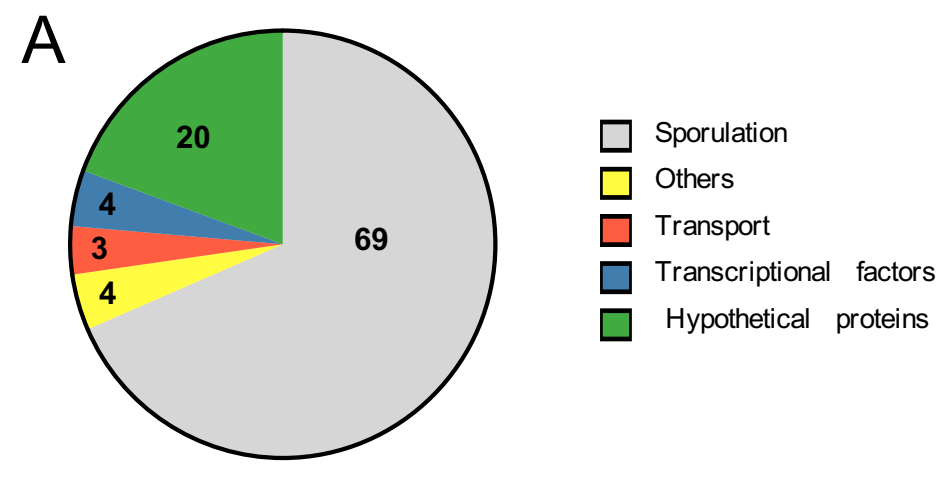

B CsiA

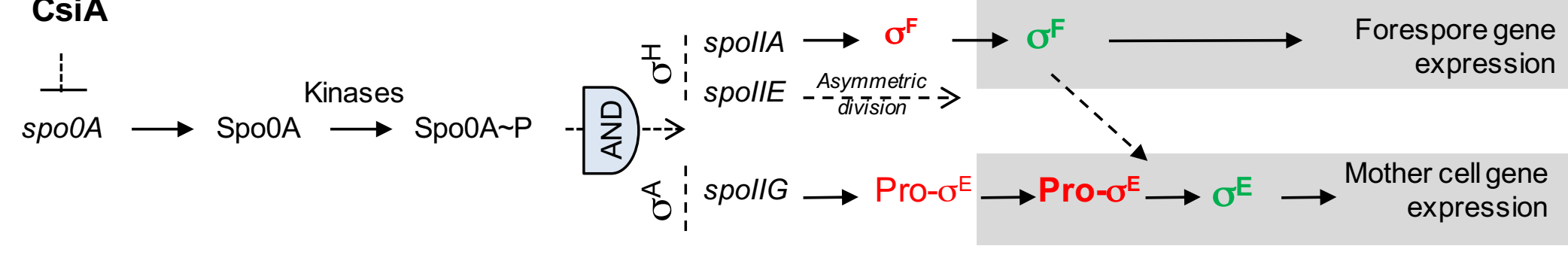

Pre-divisional cell

Sporulating cell 